\title{
Seed priming with Brassinosteroids alleviates Aluminum toxicity in rice via improving antioxidant defense system and suppressing aluminum uptake
}

\section{Farwa Basit}

Zhejiang University

Liu Jiaxin

Zhejiang University

An Jianyu

Zhejiang University

Chen Min

Zhejiang University

He Can

Zhejiang University

Zhu Xiaobo

Zhejiang University

Li Zhan

Zhejiang University

Hu Jin

Zhejiang University

Guan yajing ( $\nabla$ vcguan@zju.edu.cn )

Zhejiang University College of Agriculture and Biotechnology

\section{Research Article}

Keywords: Aluminum, Brassinosteroids, Rice, antioxidant enzyme activity, heavy metals, phytohormones

Posted Date: February 24th, 2021

DOl: https://doi.org/10.21203/rs.3.rs-212038/v1

License: (c) (1) This work is licensed under a Creative Commons Attribution 4.0 International License. Read Full License

Version of Record: A version of this preprint was published at Environmental Science and Pollution Research on September 13th, 2021. See the published version at https://doi.org/10.1007/s11356-021- 
16209-y. 
2 Seed priming with Brassinosteroids alleviates Aluminum toxicity in rice via improving antioxidant

3 defense system and suppressing aluminum uptake

4 Farwa Basit ${ }^{1 \mathrm{a}}$, Liu Jiaxin ${ }^{1 \mathrm{a}}$, An Jianyu ${ }^{1}$, Chen $\min ^{1}$, He Can ${ }^{1}$, Zhu Xiaobo ${ }^{1}$, Li Zhan ${ }^{1}$, Hu Jin ${ }^{1}$, Guan Yajing*

$5 \quad{ }^{1}$ Institute of Crop Sciences, College of Agriculture and Biotechnology, Zhejiang University, P.R, China

$6 \quad{ }^{a}$ These authors contributed equally to this work.

$7 \quad *$ Corresponding author

8 Dr. Guan Yajing

9 Associate professor

10 College of Agriculture and Biotechnology,

11 Zhejiang University, P.R, China

12 Email ID: vcguan@zju.edu.cn

13

14

15

16

17

18

19

20

21

22 
Brassinosteroids (BRs) are growth-promoting hormones that exhibit high biological activities inside numerous plant species. BRs play a protective role in plants against various stresses. In the present study, seed priming of 24-epibrassinolide $(0.01 \mu \mathrm{M})$ was used to demonstrate the mitigation effect of Aluminum $(400 \mu \mathrm{M})$ in rice plants. BRs application was found effective in control beside plants under aluminum (Al) toxicity. It enhanced seed germination energy, germination percentage as well as root length, shoots length,

31 fresh and dry weight as well under the stressed condition as well as inside control (primed with BRs).

analysis of $S O D-C u-Z n, S O D-F e, C A T a, C A T b, A P X 02$, and $A P X 08$ also supported the data related to antioxidant activities. These findings led us toward the conclusion that more induction of antioxidant activities with effective response toward other seed growth parameters with low uptake of Aluminum under $400 \mu \mathrm{M}$ Aluminum stress, 24-EBL was responsible for the mitigation of aluminum stress in rice seedlings. 
Rice is the main source to meet the hunger of underprivileged people who fulfill their nutrients from rice uptake (Huang et al. 2013). Lately, soil pollution concern is arising due to industrialization and heavy metal contamination such as cadmium $(\mathrm{Cd})$, mercury (Moghaddasi et al.) and lead $(\mathrm{Pb})$ in soil, water and air $(\mathrm{Fu}$ \&Kane 2008) is the biggest issue inside all over the world Aluminum is one of the most growths inhibiting factor inside acidic soils. Almost $30-50 \%$ of soil is polluted with aluminum word widely and $21 \%$ inside China as well (Agha et al. 2018). It directly causes influences root length as well as affects membrane lipids and other peroxidation like Fe (Mannon et al. 2004). It increases the peroxidation of lipids and enhances the action of antioxidant enzymes such as catalase, peroxidase, superoxide dismutase, and glutathione reductase (Liu et al. 2003) that lead to the plant stress stage. It is investigated that Al toxicity is also observed in shoots which are observed as an upshot of root system damage (Vitorello et al. 2005). There are some nastiest effects caused by $\mathrm{Al}$ toxicity in plants such as water relation, reduces stomatal opening, reductions of photosynthetic activity besides it; reasons chlorosis as well as necrosis of leaves. Nevertheless, it surges the level of proline (Nandi \&Neogy 2002) which performs itself as an osmoprotectant, membrane stabilizer as well as ROS vulture (Apel \&Hirt 2004). 70 various types of BRs steroidal growth-promoting hormones were identified from virtually all plants like gymnosperms, monocots, dicots, pteridophytes, and alga from various parts of plants such as pollen, flower buds, fruits, seeds, vascular cambium, leaves, shoots, and roots (Bajguz \&Hayat 2009, Haubrick important role to mitigate various plant stresses including biotic and abiotic stresses (Wu et al. 2014). 

processes, cell division, elongation, gene expression, and vascular differentiation, etc. (Bergonci et al. 2014). It improves the plant growth by enhancing the chlorophyll contents which have a crucial role to increase photosynthetic capability, improves antioxidant system capacity, surges enzymatic activity, and up-regulates stress response genes [superoxide (SOD), peroxide (POD), catalase (CAT), glutathione reeducates (GR) and ascorbate peroxide (APX)] (Liu et al. 2016, Yuan et al. 2012). Various mutants of BRs showed many kinds of growth flaws such as dwarfism, deep green leaves, late flowering, and male sterility (Chakraborty et al. 2015, Hou et al. 2017) in ideal plants Arabidopsis and Brassica (Clouse et al. 1996, Russinova et al. 2004). These investigations specify that BR has an optimistic response toward numerous types of stresses as well as it stimulates various physiological and molecular mechanisms to improve plant growth by inducing stress tolerance.

The current study is aimed to deliberate the role of Brassinosteroids in lessening aluminum stress in rice plants as well as to drill the association of antioxidant system and capability of brassinosteroids to produce resistance against aluminum stress in rice plants. In this study, the application of brassinosteroids (EBL) to alleviate the aluminum stress in rice plants is scrutinized

\subsection{Brassinosteroids (BRs) preparation} 24-Epibrassinolide (EBL) was obtained from the Institute of crop science, Zhejiang University, China. The BR was liquefied in an adequate quantity of ethanol and a stock solution of $10^{-5} \mathrm{M}$ was prepared by adding $\mathrm{ddH}_{2} \mathrm{O}$ comprising $0.05 \%$ Tween- 20 as a surfactant. 

of Seed Science, College of Agriculture and Biotechnology, Zhejiang University, China. Seeds were surface

91 sterilized by using $0.5 \% \mathrm{NaClO}$ solution for 15 minutes and then washed several times through tap water followed by washing with sterilized distilled water thrice to eradicate the smidgens of the disinfectant. Priming

93 of sterilized seeds was done at $15^{\circ} \mathrm{C}$ in darkness for $24 \mathrm{hrs}$ with $0.01 \mu \mathrm{M}$ BRs. Then, seeds were dried back to

94 their original moisture contents at room temperature. The unprimed dry seeds were used as control (CK). After priming, seed germination tests were carried out. Fifty seeds were used for each treatment positioned in a plastic germination box $(12 \mathrm{~cm} \times 18 \mathrm{~cm})$ as well as each treatment was replicated three times. Then, incubation of seeds was carried out in a germination chamber at $25^{\circ} \mathrm{C}$ under an interchanging cycle of $8 \mathrm{hr}$ lighting and $16 \mathrm{hr}$ darkness for 14 days (Zeng et al. 2006). The incubated seeds were treated with $400 \mu \mathrm{M}$ concentration of Aluminum with nutrient media solution. The composition of nutrient solution was $0.5 \mu \mathrm{M} \mathrm{MKNO}, 0.5 \mu \mathrm{M}$ $\mathrm{MCa}\left(\mathrm{NO}_{3}\right)_{2}, 0.5 \mu \mathrm{M} \mathrm{MgSO}_{4}, 2.5 \mu \mathrm{M} \mathrm{MKH}_{2} \mathrm{PO}_{4}, 2.5 \mu \mathrm{M} \mathrm{NH}{ }_{4} \mathrm{Cl}, 100 \mu \mathrm{M}$ Fe-K-EDTA, 30 $\mu \mathrm{M} \mathrm{MH}_{3} \mathrm{BO}_{3}, 5 \mu \mathrm{M}$ concentrations (100-300) $\mu \mathrm{M}$ exhibited slight damage to plant growth. Although, aluminum concentration

$106400 \mu \mathrm{M}$ was exhibited substantial damage to plant growth. However, concentrations greater than $500 \mu \mathrm{M}$ were excessively toxic for the growth of the plant. 
110 the 5th day of germination and were considered as germination energy. Then, the germination percentage was

111 calculated on day 14th. Germination Index, Mean Germination Time, as well as Vigour Index, was carried out

112 by following formulas (Hu et al. 2005)

113

$$
\mathrm{GI}=\Sigma(\mathrm{Gt} / \mathrm{Tt})
$$

$$
\mathrm{MGT}=\Sigma(\mathrm{Gt} \times \mathrm{Tt}) / \Sigma \mathrm{Gt}
$$

$$
\mathrm{VI}=\text { Germination (\%) } \times[\text { Shoot length (Clouse et al.) }+ \text { Root length (Clouse et al.) }](3)
$$

$117 \mathrm{Gt}$ is the total calculated number of germinated seeds on day $\mathrm{t}$, and $\mathrm{Tt}$ is the time conforming to $\mathrm{Gt}$ in days (Hu

118 et al. 2005). day. The plants were sampled at 21 days to make the various observations.

\subsection{Plant growth investigation}




\subsection{Measurement of photosynthetic pigments}

137 for the cunning of pigment amounts:

$$
\text { Chlorophyll b }(\mathrm{Cb})=24.96 \text { A649 - 7.32 A665 }
$$

Total chlorophyll content $=\mathrm{Ca}+\mathrm{Cb}$

141 The quantities of pigments were premeditated as milligrams per liter of plant excerpt.

\subsection{Measurement of metal contents in plant tissues}

145 The digested sample was diluted with $2 \% \mathrm{HNO}_{3}$ to a final volume of $10 \mathrm{ml}$ and sifted. The filtrate was used for

146 the analysis of $\mathrm{Al}$ and the microelements $\mathrm{Fe}^{2+}, \mathrm{Zn}^{2+}, \mathrm{Mn}^{2+}$, and macro elements calcium $\left(\mathrm{Ca}^{2+}\right)$, potassium $\left(\mathrm{K}^{+}\right)$,

147 and magnesium $\left(\mathrm{Mg}^{2+}\right)$ with an atomic absorption spectrometer (iCAT-6000-6300, Thermo Scientific, USA)

148 (Khan et al. 2013). 
151 Approximately $1.5 \mathrm{~mL}$ excerpt was homogenized in $2.5 \mathrm{~mL}$ of $5 \%$ TBA prepared in $5 \%$ trichloroacetic acid

152 (TCA). The mixture was intense at $95{ }^{\circ} \mathrm{C}$ for $15 \mathrm{~min}$, besides then hastily chilled on ice. Afterward,

153 centrifugation at 5,000 g for 10 min was carried out; the absorbance of the supernatant was calculated at 532

$154 \mathrm{~nm}$. Amendment of nonspecific turbidity was through by subtracting the absorbance value measured at $600 \mathrm{~nm}$.

155 The concentration of MDA was intended in terms of (nmol mg $\mathrm{m}^{-1}$ protein). To measure the concentration of

156 hydrogen peroxide $\left(\mathrm{H}_{2} \mathrm{O}_{2}\right)$, shadowed the protocol designated by (Velikova et al. 2000).

160 the homogenate was done for 20 minutes at $12000 \mathrm{rpm}$ at $4^{\circ} \mathrm{C}$. Supernatants were unruffled in discrete tubes and

161 stored at $80^{\circ} \mathrm{C}$. The method of Giannopolitis \& Ries, (1977) was followed to examine the activity of superoxide

162 dismutase (SOD). Peroxidase (POD) activity was assessed as designated by (Dobson \&Wilson 1992)

163 exhausting the elimination coefficient $25.5 \mathrm{mM}-1 \mathrm{~cm}-1$. Catalase (CAT) activity was inspected conferring to

164 (Aebi, 1984) by the extermination constant of $39.4 \mathrm{mM}-1 \mathrm{~cm}-1$, whereas for the fortitude of ascorbate

165 peroxidase (APX) activity scrutiny was done by the method of (Nakano \&Asada 1981).

\subsection{RNA extraction and gene expression analysis}

168 extracted grounded on the Trizol reagent as described by Gunia, Barnes, \& Sah, (2014). For cDNA synthesis,

169 reverse transcription from $1 \mu \mathrm{g}$ of total RNA through PrimeScript ${ }^{\mathrm{TM}} \mathrm{RT}$ reagent kit was utilized as well as 
171 qPCR are specified in Table S1.

\subsection{Statistical Analysis}

173 One-way analysis of variance treatments with the least significant differences (LSD) was applied as a

174 posthoc test at a 95\% assurance interlude amongst numerous data sets, using SPSS v16.0 (SPSS, Inc., Chicago,

175 IL, USA). Three samples for one treatment were conducted from three different pots. Variance (Oberdörster et

176 al.) analysis was done through Duncan's multiple range tests amongst the treatment's mean to conclude the

177 significant difference at $\mathrm{p}<0.05$ and 0.01 levels between mean values. Principle component analysis (PCA) and

178 Agglomerative hierarchical clustering (AHC) was accomplished to scrutinize the classification of two different

179 cultivars of rice grounded on their vulnerability toward Al by using XLSTAT.

\section{Results}

\subsection{Supplement of BRs significantly enhanced seed vigor and plant growth}

The current study has demonstrated that germination energy, percentage, vigor index, and germination 

as compared to cultivar YLY-689 and significant improvement in shoot length, root length, fresh weight, and

193 dry weight under $400 \mu \mathrm{M} \mathrm{Al}$ exposure were noticed with seed priming with $0.01 \mu \mathrm{M}$ BRs (Table 2).

\subsection{Seed Priming with BRs significantly increased photosynthetic pigments}

The latent study represented that alone treatment of $\mathrm{Al}$ caused a significant reduction in $\mathrm{Chl} \mathrm{a}, \mathrm{b}$ and total

196 noticed in both cultivars (Table 3-4). cultivars (Fig. 3).

chlorophyll contents as compared to control. (Fig. 3). This reduction inside photosynthetic pigments was observed in both cultivars under Al stress. The decrease was more noticeable in CY-927 as compared to YLY-689. Seed priming with $0.01 \mu \mathrm{M}$ BRs increased photosynthetic pigments such as $\mathrm{Chl} \mathrm{a}, \mathrm{b}$, and total chlorophyll contents as compared to control inside both treatments alone as well as under $400 \mu \mathrm{M} \mathrm{Al}$ stresses in both cultivars. Plants treated with BRs alone exhibited more photosynthetic pigment than control in both

\subsection{Supplement of BRs reduced $\mathrm{Al}$ accumulation under Al stress}

Roots are the main part that interacts first with heavy metals and the main source of uptake for a nutrient solution as well as heavy metals. A recent study revealed that Al uptake was more in those plants which were primed by water as compared to the plants primed with $0.01 \mu \mathrm{M}$ BRs under $\mathrm{Al}$ toxicity. In roots, $\mathrm{Al}$ accumulation was observed higher as compared to shoots (Table 3-4). More Al accumulation was pragmatic in cultivar YLY-689 as compared to CY-927. More interestingly, it was observed that K, Ca, Fe and Mn contents decreased by exposure of $\mathrm{Al}$ toxicity in both roots and shoots whereas $\mathrm{Zn}$ was increased. The same trend was

\subsection{Supplement of BRs ameliorated Al generated oxidative stress}


214 production significantly inside both cultivars (Fig. 4). The MDA contents were observed higher in shoots

215 as compared to roots under alone treatment of Al was noticed $64.7 \%$ in CY-927 and 55.4\% in YLY-689.

216 Whereas it was observed $56 \%$ and $42 \%$ in roots respectively. Moreover, $44.5 \%, 45 \%$ in shoots, and $26 \%$,

$21739.7 \%$ decreased were recorded in roots of both cultivars under primed seeds with $0.01 \mu \mathrm{M}$ BRs

218 respectively.

\section{3.5. Determination of Antioxidant enzyme activities}

220 Under alone treatment of Al, stimulated behavior of antioxidant activity was noticed. A recent investigation

221 showed that under $400 \mu \mathrm{M} \mathrm{Al}$ concentration; SOD, CAT, POD as well as APX was enhanced more in stressed

222 plants as compared to the control and this effect was observed higher in YLY-689 than CY-927 (Fig. 5). These

223 activities were observed higher in roots as compared to shoots. SOD activity under alone treatment of Al was

224 noticed at $22.5 \%$ in CY-927 and $43.6 \%$ in shoots of YLY-689 cultivar. Whereas it was observed $47.7 \%$ and

$22558.2 \%$ in roots respectively. Interestingly, $44.6 \%, 46.3 \%$ in shoots, and $57.4 \%, 58.2 \%$ increment were recorded

226 in roots of both cultivars under primed seeds with $0.01 \mu \mathrm{M}$ BRs respectively. For CAT activity, under separate

227 treatment of Al was noticed $45 \%$ in CY-927 and 59\% in YLY-689. Whereas it was observed 39\% and 45\% in

228 roots respectively. Stimulatingly, $51 \%, 61 \%$ in shoots, and $46 \%, 58 \%$ increment were recorded in roots of both

229 cultivars under primed seeds with $0.01 \mu \mathrm{M}$ BRs respectively. In the presence of Al alone, POD and APX were

230 also noticed higher but with BRs priming this effect was observed further greater however POD activity was not 
231 more enhanced. Under Al treatment, 14.8\% in CY-927, 37.4\% in YLY-689 POD was recorded in shoots as well

232 as $30.2 \%$ and $46.8 \%$ were observed in roots respectively (Fig. 5).

\subsection{Determination of gene expression analysis}

A significant difference was noted in the expression of $A P X 02$ in both roots and shoots as compared to control inside both cultivars. Transcriptional level of $A P X 02$ was higher under the stress of $400 \mu \mathrm{M} A 1$ as well as

236 with the treatment of $0.01 \mu \mathrm{M}$ BRs under $400 \mu \mathrm{M}$ toxicity. Expression of APX02 was higher in the YLY-689

237 cultivar as compared to the CY-927 rice cultivar $(\mathrm{p}<0.01)$. Interestingly, the transcriptional level of APX02 in

238 plants that were treated with seed priming of $0.01 \mu \mathrm{M}$ BRs were higher than stressed plants and data was

239 supporting the results of APX activity (Fig. 5). Correspondingly, the transcription level of APX08 was also

240 prominent in both roots and shoots inside both cultivars as compared to control but inside roots, the expression

241 level of APX08 was observed higher in YLY-689 as compared to CY-927 cultivar (Fig. 6a). Additionally, gene

242 expression of $C A T a$ and $C A T b$ in both cultivars is observed higher in both roots and shoots as well as compared

243 to the gene expression level of the control condition. It was investigated that increase was more pronounced

244 inside YLY-689 as compared to CY-927 cultivars. As a result, under $\mu \mathrm{M}$ Al stress, the gene expression level of

$245 C A T a$ and $C A T b$ was higher in both roots and shoots in both cultivars as compared to the control (Fig. 6b).

246 Significant up-regulation of $S O D \mathrm{Cu}-\mathrm{Zn}$ and $\mathrm{SOD}-\mathrm{Fe}_{2}$ gene expression was observed in both cultivars under

247 stressed conditions but it was noticed higher in YLY-689. SOD Cu-Zn and SOD-Fe 2 gene transcriptional level

248 was observed higher in roots as compared to shoots. SOD Cu-Zn gene transcriptional level was more clearly

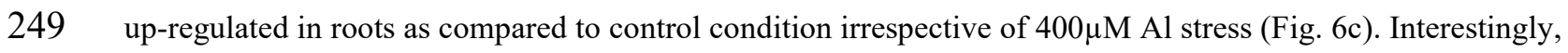

250 seeds primed with $0.01 \mu \mathrm{M}$ BRs showed higher expression of $S O D C u$-Zn and $S O D-F e_{2}$ genes as compared to

251 seeds primed with water. It may be happened to modulate the stress condition inside both cultivars by 
up-regulating specific genes expression momentarily irrespective of $400 \mu \mathrm{M} \mathrm{Al}$ toxicity concentration (Fig. 6c).

253 Our data also supports the resultant behavior of antioxidant activities (Fig. 5). It clearly showed that $0.01 \mu \mathrm{M}$

254 BRs have a significant role to cope with the stress condition as compared to control plants by modulating and

255 regulating the transcriptional expression level of specific genes

\subsection{Determination of cluster and correlation analysis between observations}

257 Based on physiological traits of two different rice varieties; biplot graphs of Principle component analysis were

258 constructed to investigate the sensitive and tolerant groups through F1 and F2 of numerous parameters under

259 distinct treatments for example control primed with water (CY927-H2O, YLY689-H2O), control primed with

260 BRs (CY927-BRs, YLY689-BRs), seed primed with BRs, and treatment under Al stress (CY927-BRs+Al,

261 YLY689-BRs+Al), seed primed with H2O under Al stress(CY92-Al+ H2O, YLY689- Al+ H2O) (Fig7A-C).

262 MDA, MGT, and $\mathrm{H} 2 \mathrm{O} 2$ were grouped and represented a positive correlation between each other. Although,

263 MGT, H2O2, and MDA showed a significantly negative correlation with V.I, F/W, D/W, S.L, R.L, G.E, and

264 G.P but simultaneously exhibited a negative correlation with SOD, POD, CAT, and APX as well. A similar

265 trend was noticed in both varieties (Fig. 7A, and B). PCA analysis of both cultivars (CY927 and YLY689)

266 demonstrated that YLY689 is a tolerant genotype to $\mathrm{Al}$ and CY927as a sensitive genotype. It demonstrated the

267 maximum contribution of F1 (84.92) followed by F2 (10.20), with total contribution of $95.12 \%$ in CY927 and

268 for YLY689 the maximum contribution of F1 (86.39) followed by F2 (10.69), with total contribution of 97.09\%

269 is noticed. ACH outcomes also confirmed the same response of both varieties under distinct treatments (Fig.

270 7C). It represented the close correlation between both cultivars (CY927 and YLY689) primed with BRs as well

271 as primed with water than cultivars primed with water under $\mathrm{Al}$ stress. Cultivars primed with $\mathrm{BRs}$ under $\mathrm{Al}$ 

with water under $\mathrm{Al}$ toxicity $(7 \mathrm{C})$.

\section{Discussion}

At $\mathrm{pH}$ less than 5.5, $\mathrm{Al}$ is present in an available form which can cause toxicity in plants especially inhibit the roots of plants; (Barcelo \&Poschenrieder 2002) reduce shoots length, fresh weight, and dry weight (Table 2)

279 because it has direct exposure to roots and cause inhibition of cell elongation at an early stage and later on cause processes are also affected (Fig. 3) resultant in a caused reduction in plant growth by $\mathrm{Al}$ exposure (Table 2).

288 Nevertheless, seeds treated with brassinosteroids (24 EBL) priming showed better response toward Al stress 289 resistance as compared to seeds primed with water (Table 1-2) and enhanced the photosynthetic pigments inside 290 both sensitive, as well as tolerant variety under Al toxicity (Fig. 3) due to the brassinosteroids, stress resistance

291 behavior in amendments and manipulations in plasma membrane under stressed environment (Hamada $292 \&$ Tsuruo 1986) as well as with stimulating the antioxidant enzyme activity (Fig. 5) Moreover, Brassinosteroids 
294 of genes, protein synthesis (Brand et al. 2003) besides nucleic acid stimulation as well as improvement in 295 antioxidant enzyme activity (Khripach et al. 2003). All of these modified effects of brassinosteroids play an 296 important role to stimulate plant growth under stressed conditions. It was reported that $\mathrm{Al}$ reduces the stress 297 effect on plants and improves plant growth as well as photosynthetic pigments and water uptake (Abdullahi et 298 al. 2003, Rajewska et al. 2016). Likewise, It inhibited toxicity caused by cadmium in cowpea plants (Santos et 299 al. 2018), reduced salinity stress (Guinney et al. 2015, O“ zdemir \&Edwards 2004), Chromium stress in 300 Brassica Juncea L. (Arora et al. 2010), temperature stress (Di Angelantonio et al. 2016, Finlayson \&Van der 301 Valk 1995), drought (FILOVÁ 2014, Talaat \&Shawky 2016, Talaat et al. 2015) and heavy metal stresses (Li et al. 2016, Singhal et al. 2015, Swamy et al. 2014) as well by improving antioxidant system.

303 The results obtained from present studies that antioxidant enzyme activities such as catalase (CAT), ascorbate 304 peroxidase (APX), superoxide dismutase (SOD) which acts as a defense system during plant stress periods are increased by aluminum stress (Fig. 5) because of interference inside ROS activity (Jones et al. 2006, Yamamoto et al. 2003b). In a likewise recent study, SOD, CAT, and APX have increased in both sensitive as well as tolerant varieties in maize after exposure to Al treatment alone (Liu et al. 2008, Yamamoto et al. 2003a). In

308 tobacco plants, SOD, POD, APX, and CAT activity was increased after Al disclosure (Ghanati et al. 2005).

309 Interestingly, in latent investigation brassinosteroids stimulated more antioxidant activities in both pensive and 310 resistant cultivars (Fig. 5). The role of antioxidant activities i.e. SOD, POD, and CAT, etc. is very important and 311 it is enhanced by BRs after Al exposure to reduce the toxicity induced by Al (Padmanabhan et al. 2010). It's 312 found consistent in various studies that BRs increase the antioxidant enzymatic activity in stress conditions to 313 mitigate various stresses and to (Arora et al. 2008, Bajguz \&Hayat 2009) regulate plant's normal behavior (Ali 314 et al. 2008, Sharma et al. 2007). Al stress causes damage inside the membrane as a result hydrolytic enzyme 315 activity reduces and causes enhancement of ROS activity (Fig. 4). It is strongly believed that an increase in ROS 
316 activity causes severe damage inside cellular structure as well as to macromolecules (Halliwell 1999). It is noted

317 that the application of BRs reduces $\mathrm{H}_{2} \mathrm{O}_{2}$ production as well as MDA content under a stress environment (Fig.

318 4) to protect the plant's membrane from oxidative damage. It lessens the rate of superoxide radicles and as a

319 result enhances the antioxidant activity in plants (Singh et al. 2008).

320 Gene expression study by checking the transcriptional level of plants under heavy metal stress provides a more

321 precise approximation of antioxidant genes toward the behavior of antioxidant enzyme activities. Hence, we

322 investigated multiple genes related to antioxidant activities to estimate both enzymatic as well as transcriptional

323 responses of both rice cultivars under stress conditions as compared to control. Transcriptional levels of APX02

324 and $A P X 08$ were higher in our study. This expression has gone toward up-regulation because of $\mathrm{NaCl}$ treatment

325 (Matsumoto et al. 2001). Likewise, APX transcripts influence was up-regulated through augmented levels of

$326 \mathrm{H}_{2} \mathrm{O}_{2}$ in tobacco chloroplasts as consequences of $\mathrm{Cu}$ - $\mathrm{Zn}$-superoxide dismutase overexpression (Gupta et al.

327 1993). Moreover, significant up-regulation of catalase genes (CATa and $C A T b)$ was also observed in both roots

328 and shoots inside both cultivars. There is no significant change in catalase gene expression of leaves were

329 investigated in Arabidopsis thaliana (Mol et al. 2008). It may have occurred because of the presence of multiple

330 allo- or isozymes. In contrast, $\mathrm{Al}$ causes an increase of catalase gene expression because of the breakdown of

331 proteins which leads to up-regulation of the transcriptional level. In the present investigation, it is also examined

332 that gene expression $\mathrm{SOD}-\mathrm{Cu}-\mathrm{Zn}$ and $\mathrm{SOD}-\mathrm{Fe}_{2}$ were higher under Aluminium stress which indicated that

333 oxidative damage inside various cellular compartments were induced by Al toxicity. The pattern of gene

334 regulation was different because its expression was more up-regulated in roots as compared to shoots in both

335 cultivars as compared to control. It may happen because roots are the plant's primary interaction point which

336 first interacts with toxicity caused by Al stress. These interpretations reinforced the opinion of Smeets et al. who

337 specified that the fundamental mechanism of oxidative stress was dissimilar in the roots as compared to leaves. 
338 Furthermore, the generation of superoxide besides the lipoxygenase activity is the foremost reason for oxidative

339 stress inside roots, although inside the leaves $\mathrm{H}_{2} \mathrm{O}_{2}$ was appeared to be an imperative contestant. However, $\mathrm{H}_{2} \mathrm{O}_{2}$

340 was formed close by as a product of augmented $\mathrm{Cd}$ content of the leaves, or maybe it attained as an indication

341 from roots, rests to be illuminated (Mol et al. 2008).

342 Principle component analysis (PCA) is a multivariate method which frequently used to categorize the values

343 based on various biological statuses, quality as well as origins. To identify and categorize the large data set into

344 a small number of vigorously correlated variables PCA is utilized (Shan et al. 2013). ACH disclosed the

345 interaction between different genotypes of rice-based on distinct treatments (Fig 7C). On physiological traits

346 based, various treatments were utilized to distinguish the sensitive and tolerant genotype and to represent the

347 correlation between various traits by using the amalgamation of both PCA and ACH (Fig. 5). V.I, F/W, D/W,

348 S.L, R.L, G.E, and G.P were showed a group and significantly positive correlation between each other but

349 instantaneously negative relation with MGT, H2O2, and MDA. This investigation contributes to cognize the

350 response mechanism of both cultivars (CY927, YLY689) under Al stress as well as seed priming with BRs

351 under $\mathrm{Al}$ toxicity in both varieties on morphophysiological, biochemical, and molecular bases.

\section{Conclusion}

The latest study investigated the clear phytotoxic effect of aluminum (Al) on the physiological,

354 antioxidant system as well as on the molecular mechanism of rice seedling. Data exposed that seed priming with

355 brassinosteroids (BRs) mitigated the venomous effect of aluminum to Oryza sativa seeds besides enhanced both

356 germination as well as early seedling growth under toxicity of Al. Antioxidant system (SOD, POD, CAT, and

357 APX) was increased by the response of Al stress in rice plants which was remarkably further persuaded by BRs.

358 Furthermore, a transcriptional study of antioxidant genes also confirmed the same pattern in both cultivars.

359 Consequently, it may be suggested that the modified level of the antioxidant system, however in part, was the 
361 YLY-689 proved as a tolerant variety as compared to CY-927 against Al toxicity. Furthermore, the application

362 of BRs increased the degree of resistance by enhancing plant growth, photosynthetic pigments, and other

363 associated processes under aluminum stress inside rice seedlings.

\section{Author contribution}

$365 \mathrm{FB}, \mathrm{HJ}$, and GY involved in conceptualization, GY and FB design experiment. FB, AJ, LZ performed 366 experiment and writing manuscript. HC, LJ and CM writing and editing assistance the manuscript. $\mathrm{HJ}$ and ZX 367 perform statistical analysis. All authors read and approved the final manuscript.

\section{Conflict of interest}

369 The authors declare that they have no conflict of interest.

\section{$370 \quad$ Funding}

371 The authors did not receive support from any organization for the submitted work.

\section{Data availability statement}

373 All data generated or analyzed during this study are included in this published article.

\section{Ethics approval and consent to participate}

375 Not applicable.

\section{Consent for publication}

377 Not applicable.

\section{Competing interests}

379 The authors declare that they have no competing interests.

\section{$380 \quad$ References}

381 Abdullahi I, Winter S, Atiri G, Thottappilly G (2003) Molecular characterization of whitefly, Bemisia tabaci 
Agha RA, Borrelli MR, Farwana R, Koshy K, Fowler AJ, Orgill DP, Zhu H, Alsawadi A, Noureldin A, Rao A (2018) The SCARE 2018 statement: updating consensus Surgical CAse REport (SCARE) guidelines. Int J Surg 60:132-136

Ali M, Schiedt B, Healy K, Neumann R, Ensinger W (2008) Modifying the surface charge of single track-etched conical nanopores in polyimide. Nanotechnology 19:085713

Apel K, Hirt H (2004): Reactive oxygen species: metabolism, oxidative stress, and signal transduction. Annu. Rev Plant Biol 55:373-399

Arora A, Ceccagnoli M, Cohen WM (2008) R\&D and the patent premium. INT J IND ORGAN 26:1153-1179

Arora P, Bhardwaj R, Kanwar MK (2010) 24-Epibrassinolide induced antioxidative defense system of Brassica juncea L. under Zn metal stress. PHYSIOL MOL BIOL PLA 16:285-293

Bajguz A, Hayat S (2009) Effects of brassinosteroids on the plant responses to environmental stresses. Plant Physiol Biochem 47:1-8

Barcelo J, Poschenrieder C (2002) Fast root growth responses, root exudates, and internal detoxification as clues to the mechanisms of aluminium toxicity and resistance: a review. ENVIRON EXP BOT 48:75-92

Bergonci T, Ribeiro B, Ceciliato PH, Guerrero-Abad JC, Silva-Filho MC, Moura DS (2014) Arabidopsis thaliana RALF1 opposes brassinosteroid effects on root cell elongation and lateral root formation. J. Exp Bot 65:2219-2230

Brand S, Felner R, Shim M, Seitsinger A, Dumas T (2003) Middle school improvement and reform: Development and validation of a school-level assessment of climate, cultural pluralism, and school safety. J Educ Psychol 95:570

Castro SSd, Abdala K, Silva AA, Bôrges VMS (2010) A expansão da cana-de-açúcar no cerrado e no estado de Goiás: elementos para uma análise espacial do processo.

Chakraborty N, Sharma P, Kanyuka K, Pathak RR, Choudhury D, Hooley R, Raghuram N (2015) G-protein $\alpha$-subunit (GPA1) regulates stress, nitrate and phosphate response, flavonoid biosynthesis, fruit/seed development and substantially shares GCR1 regulation in A. thaliana.

Plant

Mol

Biol $89: 559-576$

Čiamporová M (2002) Morphological and structural responses of plant roots to aluminium at organ, tissue, and cellular levels. Biol Plant 45:161-171 
Clouse SD, Langford M, McMorris TC (1996) A brassinosteroid-insensitive mutant in Arabidopsis thaliana exhibits multiple defects in growth and development. Plant Physiol 111:671-678

da Silva Leite SA (2012): Afetividade nas práticas pedagógicas. Temas em psicologia 20:355-368

Dawe D, Pandey S, Nelson A (2010) Emerging trends and spatial patterns of rice production. Rice in the global economy: strategic research and policy issues for food security. Los Banos, Philippines: Int Rice Res (IRRI)

Di Angelantonio E, Bhupathiraju SN, Wormser D, Gao P, Kaptoge S, de Gonzalez AB, Cairns BJ, Huxley R, Jackson CL, Joshy G (2016) Body-mass index and all-cause mortality: individual-participant-data meta-analysis of 239 prospective studies in four continents. Lancet 388:776-786

Dobson J, Wilson M (1992) Sensitization of oral bacteria in biofilms to killing by light from a low-power laser Arch Oral Biol 37:883-887

FILOVÁ A (2014) Production of secondary metabolities in plant tissue cultures. J Agric Sci 46

Finlayson C, Van der Valk A (1995) Wetland classification and inventory: a summary. Vegetatio $118: 185-192$

Fu L, Kane CL (2008) Superconducting proximity effect and Majorana fermions at the surface of a topological insulator. Phys Rev Lett 100:096407

Ghanati F, Morita A, Yokota H (2005) Effects of aluminum on the growth of tea plant and activation of antioxidant system. Plant Soil 276:133-141

Guinney J, Dienstmann R, Wang X, De Reyniès A, Schlicker A, Soneson C, Marisa L, Roepman P, Nyamundanda G, Angelino P (2015) The consensus molecular subtypes of colorectal cancer. Nat Med 21:1350-1356

Gupta AS, Webb RP, Holaday AS, Allen RD (1993) Overexpression of superoxide dismutase protects plants from oxidative stress (induction of ascorbate peroxidase in superoxide dismutase-overexpressing plants). Plant Physiol 103:1067-1073

Halliwell B (1999) Antioxidant defence mechanisms: from the beginning to the end (of the beginning). Free Radic 31:261-272

Hamada H, Tsuruo T (1986) Functional role for the 170-to 180-kDa glycoprotein specific to drug-resistant tumor cells as revealed by monoclonal antibodies. Proc Natl Acad Sci USA 83:7785-7789 
Haubrick LL, Assmann SM (2006) Brassinosteroids and plant function: some clues, more puzzles. Plant Cell Environ 29:446-457

Hou S, He J, Parikh A, Kahl D, Bertulani C, Kajino T, Mathews G, Zhao G (2017) Non-extensive statistics to the cosmological lithium problem. Astrophys J 834:165

Hu J, Chen G, Lo IM (2005) Removal and recovery of Cr (VI) from wastewater by maghemite nanoparticles. Water Res 39:4528-4536

Huang Z, Pan X-D, Wu P-G, Han J-L, Chen Q (2013) Health risk assessment of heavy metals in rice to the population in Zhejiang, China. PloS one 8:e75007

Jones D, Blancaflor E, Kochian L, Gilroy S (2006) Spatial coordination of aluminium uptake, production of reactive oxygen species, callose production and wall rigidification in maize roots. Plant Cell Environ 29:1309-1318

Khan HAA, Shad SA, Akram W (2013) Resistance to new chemical insecticides in the house fly, Musca domestica L., from dairies in Punjab, Pakistan. Parasitol Res 112:2049-2054

Khripach VA, Zhabinskii VN, Khripach NB (2003) New practical aspects of brassinosteroids and results of their ten-year agricultural use in Russia and Belarus, Brassinosteroids. Springer pp. 189-230

Latha P, Vidya Vardhini B (2018) Effect of homobrassinolide on the growth of mustard crops grown in semi-arid tropics of nizamabad. Int J Curr Res 7:2320-2326

Leaska MA (1970) Virginia Woolf's Lighthouse: a study in critical method. Chatto \& Windus

Li J, Galley M, Brockett C, Spithourakis GP, Gao J, Dolan B (2016) A persona-based neural conversation model. arXiv preprint arXiv:1603.06155

LICHTENTHALER HK, Wellburn AR (1983) Determinations of total carotenoids and chlorophylls a and b of leaf extracts in different solvents. Portland Press Ltd.

Liu C-W, Lin K-H, Kuo Y-M (2003) Application of factor analysis in the assessment of groundwater quality in a blackfoot disease area in Taiwan. Sci Total Environ 313:77-89

Liu Q, Yang J, He L, Li Y, Zheng S (2008) Effect of aluminum on cell wall, plasma membrane, antioxidants and root elongation in triticale. Biol Plant 52:87-92

Liu XS, Wu H, Ji X, Stelzer Y, Wu X, Czauderna S, Shu J, Dadon D, Young RA, Jaenisch R (2016) Editing DNA methylation in the mammalian genome. Cell 167:233-247. e17 
Mannon PJ, Fuss IJ, Mayer L, Elson CO, Sandborn WJ, Present D, Dolin B, Goodman N, Groden C, Hornung RL (2004) Anti-interleukin-12 antibody for active Crohn's disease. N Engl J Med 351:2069-2079

Matsumoto Y, Murakami M, Shono T, Hasegawa T, Fukumura T, Kawasaki M, Ahmet P, Chikyow T, Koshihara S-y, Koinuma H (2001) Room-temperature ferromagnetism in transparent transition metal-doped titanium dioxide. Science 291:854-856

Mei H, Li Z, Shu Q, Guo L, Wang Y, Yu X, Ying C, Luo L (2005) Gene actions of QTLs affecting several agronomic traits resolved in a recombinant inbred rice population and two backcross populations. THEOR APPL GENET 110:649-659

Moghaddasi S, Fotovat A, Khoshgoftarmanesh AH, Karimzadeh F, Khazaei HR, Khorassani R (2017) Bioavailability of coated and uncoated $\mathrm{ZnO}$ nanoparticles to cucumber in soil with or without organic matter. Ecotoxicol 144:543-551

Mol SE, Bus AG, De Jong MT, Smeets DJ (2008) Added value of dialogic parent-child book readings: A meta-analysis. Early Educ Dev 19:7-26

Nakano Y, Asada K (1981) Hydrogen peroxide is scavenged by ascorbate-specific peroxidase in spinach chloroplasts. PLANT CELL PHYSIOL 22:867-880

Nandi A, Neogy S (2002) Modelling of a beam with a breathing edge crack and some observations for crack detection. J Vib Control 8:673-693

O” zdemir AT, Edwards L (2004) Through-thickness residual stress distribution after the cold expansion of fastener holes and its effect on fracturing. J Eng Mater Technol 126:129-135

Oberdörster G, Maynard A, Donaldson K, Castranova V, Fitzpatrick J, Ausman K, Carter J, Karn B, Kreyling W, Lai D (2005) Principles for characterizing the potential human health effects from exposure to nanomaterials: elements of a screening strategy. PART FIBRE TOXICOL 2:8

Olivares A, Daza A, Rey A, Lopez-Bote C (2009) Interactions between genotype, dietary fat saturation and vitamin A concentration on intramuscular fat content and fatty acid composition in pigs. Meat Sci $82: 6-12$

Padmanabhan S, Melander O, Johnson T, Di Blasio AM, Lee WK, Gentilini D, Hastie CE, Menni C, Monti MC, Delles C (2010) Genome-wide association study of blood pressure extremes identifies variant near UMOD associated with hypertension. PLoS Genet 6:e1001177 
Piotrowska-Niczyporuk A, Bajguz A (2014) The effect of natural and synthetic auxins on the growth, metabolite content and antioxidant response of green alga Chlorella vulgaris (Trebouxiophyceae). Plant Growth Regul 73:57-66

Rajewska I, Talarek M, Bajguz A (2016) Brassinosteroids and response of plants to heavy metals action. FRONT PLANT SCI 7:629

Russinova E, Borst J-W, Kwaaitaal M, Caño-Delgado A, Yin Y, Chory J, de Vries SC (2004) Heterodimerization and endocytosis of Arabidopsis brassinosteroid receptors BRI1 and AtSERK3 (BAK1). Plant Cell 16:3216-3229

Santos L, Batista B, Lobato A (2018) Brassinosteroids mitigate cadmium toxicity in cowpea plants. Photosynthetica 56:591-605

Shan Y, Arkhipov A, Kim ET, Pan AC, Shaw DE (2013) Transitions to catalytically inactive conformations in EGFR kinase. Proc Natl Acad Sci USA 110:7270-7275

Sharma R, Duveiller E, Ortiz-Ferrara G (2007) Progress and challenge towards reducing wheat spot blotch threat in the Eastern Gangetic Plains of South Asia: is climate change already taking its toll? Field Crops Res 103:109-118

Silambarasan S, Logeswari P, Cornejo P, Kannan VR (2019) Role of plant growth-promoting rhizobacterial consortium in improving the Vigna radiata growth and alleviation of aluminum and drought stresses. ENVIRON SCI POLLUT R 26:27647-27659

Simon L, Smalley T, Jones Jr JB, Lasseigne F (1994) Aluminum toxicity in tomato. Part 1. Growth and mineral nutrition. J Plant 17:293-306

Singh N, Kamath V, Narasimhamurthy K, Rajini P (2008) Protective effect of potato peel extract against carbon tetrachloride-induced liver injury in rats. ENVIRON TOXICOL PHAR 26:241-246

Singhal R, Chung S-H, Manthiram A, Kalra V (2015) A free-standing carbon nanofiber interlayer for high-performance lithium-sulfur batteries. J Mater Chem A 3:4530-4538

Swamy M, Norlina W, Azman W, Suhaili D, Sirajudeen K, Mustapha Z, Govindasamy C (2014) Restoration of glutamine synthetase activity, nitric oxide levels and amelioration of oxidative stress by propolis in kainic acid mediated excitotoxicity. AFR J TRADIT COMPLEM 11:458-463 
Talaat NB, Shawky BT (2016) Dual application of 24-epibrassinolide and spermine confers drought stress tolerance in maize (Zea mays L.) by modulating polyamine and protein metabolism. J Plant Growth Regul 35:518-533

Talaat RM, Mohamed SF, Bassyouni IH, Raouf AA (2015) Th1/Th2/Th17/Treg cytokine imbalance in systemic lupus erythematosus (SLE) patients: Correlation with disease activity. Cytokine 72:146-153

Velikova V, Yordanov I, Edreva A (2000) Oxidative stress and some antioxidant systems in acid rain-treated bean plants: protective role of exogenous polyamines. PLANT SCI 151:59-66

Vitorello VA, Capaldi FR, Stefanuto VA (2005) Recent advances in aluminum toxicity and resistance in higher plants. $\quad$ Braz J Plant Physiol 17:129-143

Wu Z, Wang S, Zhao J, Chen L, Meng H (2014) Synergistic effect on thermal behavior during co-pyrolysis of lignocellulosic biomass model components blend with bituminous coal. Bioresour Technol $169: 220-228$

Yamamoto M, Sato S, Hemmi H, Hoshino K, Kaisho T, Sanjo H, Takeuchi O, Sugiyama M, Okabe M, Takeda K (2003a) Role of adaptor TRIF in the MyD88-independent toll-like receptor signaling pathway. Science 301:640-643

Yamamoto Y, Kobayashi Y, Devi SR, Rikiishi S, Matsumoto H (2003b) Oxidative stress triggered by aluminum in plant roots, Roots: The Dynamic Interface between Plants and the Earth. Springer pp. $239-243$

Yuan L, Yuan Y, Du J, Sun J, Guo S (2012) Effects of 24-epibrassinolide on nitrogen metabolism in cucumber seedlings under Ca (NO3) 2 stress. J Plant Physiol Biochem 61:29-35

Zeng M-H, Wang B, Wang X-Y, Zhang W-X, Chen X-M, Gao S (2006) Chiral magnetic metal-organic frameworks of dimetal subunits: magnetism tuning by mixed-metal compositions of the solid solutions. Inorg Chem 45:7069-7076

Zhang J, Terrones M, Park CR, Mukherjee R, Monthioux M, Koratkar N, Kim YS, Hurt R, Frackowiak E, Enoki T (2016) Carbon science in 2016: Status, challenges and perspectives. Carbon 98:708-732 
551 Table 1. Seed priming effect with $0.01 \mu \mathrm{M}$ BRs on germination energy, germination percentage, germination

552 index, mean germination time as well as vigour index of two rice cultivars under $400 \mu \mathrm{M}$ Al toxicity.

\begin{tabular}{llllll}
\hline Varieties Name & G.E & G.P & G.I & MGT & V.I \\
\hline CY-927- $\mathrm{H}_{2} \mathrm{O}$ & $88.00 \mathrm{a} \pm 2.00$ & $94.67 \mathrm{~b} \pm 1.15$ & $20.13 \mathrm{~b} \pm 1.17$ & $2.91 \mathrm{~b} \pm 0.17$ & $0.88 \mathrm{~b} \pm 0.17$ \\
CY-927-Al & $46.00 \mathrm{~d} \pm 2.00$ & $60.67 \mathrm{~d} \pm 1.15$ & $10.87 \mathrm{c} \pm 0.50$ & $3.81 \mathrm{a} \pm 0.08$ & $0.15 \mathrm{c} \pm 0.07$ \\
CY927-BRs & $90.67 \mathrm{a} \pm 3.06$ & $100.00 \mathrm{a} \pm 0.00$ & $31.62 \mathrm{a} \pm 0.92$ & $2.17 \mathrm{c} \pm 0.07$ & $1.47 \mathrm{a} \pm 0.16$ \\
CY927-BRs+Al & $69.33 \mathrm{c} \pm 3.06$ & $85.33 \mathrm{c} \pm 5.03$ & $21.49 \mathrm{~b} \pm 1.82$ & $2.91 \mathrm{~b} \pm 0.20$ & $0.64 \mathrm{~b} \pm 0.06$ \\
YLY689- $\mathrm{H}_{2} \mathrm{O}$ & $90.00 \mathrm{~b} \pm 2.00$ & $99.33 \mathrm{a} \pm 1.15$ & $23.72 \mathrm{~b} \pm 0.43$ & $2.59 \mathrm{bc} \pm 0.26$ & $1.26 \mathrm{~b} \pm 0.15$ \\
YLY-689-Al & $69.33 \mathrm{c} \pm 1.15$ & $72.67 \mathrm{c} \pm 2.31$ & $16.53 \mathrm{c} \pm 0.58$ & $2.88 \mathrm{a} \pm 0.37$ & $0.37 \mathrm{~d} \pm 0.19$ \\
YLY689-BRs & $98.00 \mathrm{a} \pm 2.00$ & $100.00 \mathrm{a} \pm 0.00$ & $32.44 \mathrm{a} \pm 1.12$ & $1.93 \mathrm{c} \pm 0.14$ & $2.06 \mathrm{a} \pm 0.03$ \\
YLY689-BRs+Al & $80.67 \mathrm{~b} \pm 3.06$ & $88.00 \mathrm{~b} \pm 2.00$ & $23.57 \mathrm{~b} \pm 0.56$ & $2.63 \mathrm{~b} \pm 0.08$ & $0.74 \mathrm{c} \pm 0.03$ \\
\hline
\end{tabular}

553 Each value is demonstrating the mean of three repeats of every treatment. The similar letters inside a column

554 specify that there was no significant difference at a $95 \%$ probability level at the $p<0.05$ level,

555 correspondingly.

556 Table 2. Seed priming effect with $0.01 \mu \mathrm{M}$ BRs on shoot length, root length, fresh weight and dry weight of

557 two rice cultivars under $400 \mu \mathrm{M} \mathrm{Al}$ toxicity.

\begin{tabular}{lllll}
\hline Varieties Name & S.L & R.L & F/W & D/W \\
\hline CY-927- $\mathrm{H}_{2} \mathrm{O}$ & $14.26 \mathrm{~b} \pm 0.12$ & $13.85 \mathrm{~b} \pm 0.37$ & $0.41 \mathrm{~b} \pm 0.01$ & $0.04 \mathrm{a} \pm 0.01$ \\
CY-927-Al & $5.52 \mathrm{c} \pm 0.23$ & $6.85 \mathrm{~d} \pm 0.15$ & $0.16 \mathrm{~d} \pm 0.01$ & $0.01 \mathrm{c} \pm 0.01$ \\
CY927-BRs & $16.40 \mathrm{a} \pm 0.08$ & $15.29 \mathrm{a} \pm 0.44$ & $0.53 \mathrm{a} \pm 0.01$ & $0.05 \mathrm{a} \pm 0.00$ \\
CY927-BRs+Al & $8.38 \mathrm{~b} \pm 0.72$ & $8.93 \mathrm{c} \pm 0.46$ & $0.29 \mathrm{c} \pm 0.01$ & $0.03 \mathrm{~b} \pm 0.00$ \\
YLY689- $\mathrm{H}_{2} \mathrm{O}$ & $15.26 \mathrm{a} \pm 0.35$ & $18.96 \mathrm{~b} \pm 0.47$ & $0.48 \mathrm{~b} \pm 0.01$ & $0.06 \mathrm{a} \pm 0.00$ \\
YLY-689-Al & $8.56 \mathrm{~d} \pm 0.15$ & $9.19 \mathrm{~d} \pm 0.32$ & $0.18 \mathrm{~d} \pm 0.01$ & $0.02 \mathrm{c} \pm 0.01$ \\
YLY689-BRs & $18.23 \mathrm{a} \pm 0.11$ & $19.54 \mathrm{a} \pm 0.28$ & $0.59 \mathrm{a} \pm 0.01$ & $0.06 \mathrm{a} \pm 0.01$ \\
YLY689-BRs $+\mathrm{Al}$ & $11.43 \mathrm{c} \pm 0.22$ & $11.48 \mathrm{c} \pm 0.18$ & $0.31 \mathrm{c} \pm 0.01$ & $0.04 \mathrm{~b} \pm 0.00$ \\
\hline
\end{tabular}


558 Each value is demonstrating the mean of three repeats of every treatment. The similar letters inside a column

559 specify that there was no significant difference at a $95 \%$ probability level at the $p<0.05$ level,

560 correspondingly.

561 Table 3. Seed priming effect with $0.01 \mu \mathrm{M}$ BRs on Al uptake and accumulation in shoots of two rice cultivars

562 under $400 \mu \mathrm{M} \mathrm{Al}$ toxicity

\begin{tabular}{llllllll}
\hline \multirow{2}{*}{ Treatment } & $\mathbf{M g}$ & $\mathbf{A l}$ & $\mathbf{K}$ & $\mathbf{C a}$ & $\mathbf{M n}$ & $\mathbf{F e}$ & $\mathbf{Z n}$ \\
\cline { 2 - 8 } & $\mathbf{m g} / \mathbf{g}$ & $\mathbf{m g} / \mathbf{g}$ & $\mathbf{m g} \mathbf{l}$ & $\mathbf{m g} / \mathbf{l}$ & $\mathbf{m g} / \mathbf{l}$ & $\mathbf{m g} / \mathbf{l}$ & $\mathbf{m g} / \mathbf{l}$ \\
\hline $\mathrm{CY927-} \mathrm{H}_{2} \mathrm{O}$ & $2.32 \mathrm{c} \pm 0.13$ & - & $31.72 \mathrm{~d} \pm 1.06$ & $1.59 \mathrm{ab} \pm 1.04$ & $0.27 \mathrm{ab} \pm 0.10$ & $0.13 \mathrm{~b} \pm 0.10$ & $0.05 \mathrm{~b} \pm 0.02$ \\
CY927-BRs & $2.37 \mathrm{~b} \pm 0.74$ & - & $32.43 \mathrm{~b} \pm 2.06$ & $2.80 \mathrm{a} \pm 0.99$ & $0.43 \mathrm{a} \pm 0.19$ & $0.20 \mathrm{a} \pm 0.19$ & $0.05 \mathrm{~b} \pm 0.02$ \\
CY927-Al & $2.45 \mathrm{a} \pm 0.46$ & $0.61 \mathrm{a} \pm 0.06$ & $37.48 \mathrm{a} \pm 1.78$ & $1.18 \mathrm{ab} \pm 0.24$ & $0.09 \mathrm{~b} \pm 0.01$ & $0.08 \mathrm{~b} \pm 0.01$ & $0.07 \mathrm{a} \pm 0.01$ \\
CY927-BRs+Al & $2.31 \mathrm{~d} \pm 0.17$ & $0.43 \mathrm{~b} \pm 0.07$ & $32.08 \mathrm{c} \pm 1.10$ & $0.80 \mathrm{~b} \pm 0.09$ & $0.12 \mathrm{~b} \pm 0.02$ & $0.11 \mathrm{~b} \pm 0.02$ & $0.06 \mathrm{~b} \pm 0.00$ \\
YLY689-H $\mathrm{O}$ & $1.77 \mathrm{c} \pm 0.78$ & - & $26.36 \mathrm{c} \pm 1.99$ & $0.71 \mathrm{~b} \pm 0.48$ & $0.15 \mathrm{a} \pm 0.48$ & $0.07 \mathrm{a} \pm 0.04$ & $0.02 \mathrm{c} \pm 0.01$ \\
YLY689-BRs & $2.20 \mathrm{~b} \pm 0.65$ & - & $32.09 \mathrm{bc} \pm 1.93$ & $0.75 \mathrm{ab} \pm 0.21$ & $0.14 \mathrm{a} \pm 0.23$ & $0.09 \mathrm{a} \pm 0.02$ & $0.03 \mathrm{c} \pm 0.00$ \\
YLY689-Al & $2.24 \mathrm{ab} \pm 0.21$ & $0.82 \mathrm{a} \pm 0.34$ & $40.43 \mathrm{~b} \pm 2.21$ & $0.80 \mathrm{ab} \pm 0.23$ & $0.10 \mathrm{~b} \pm 0.21$ & $0.07 \mathrm{a} \pm 0.01$ & $0.05 \mathrm{a} \pm 0.01$ \\
YLY689-BRs+Al & $3.04 \mathrm{a} \pm 0.30$ & $0.24 \mathrm{~b} \pm 0.26$ & $49.60 \mathrm{a} \pm 0.52$ & $1.29 \mathrm{a} \pm 0.27$ & $0.13 \mathrm{a} \pm 0.27$ & $0.10 \mathrm{a} \pm 0.01$ & $0.04 \mathrm{~b} \pm 0.00$ \\
\hline
\end{tabular}

563 Each value is demonstrating the mean of three repeats of every treatment. Same letters are representing no

564 significant differentiation at $95 \%$ probability level $(\mathrm{p}<0.05)$

565 Table 4. Seed priming effect with $0.01 \mu \mathrm{M}$ BRs on Al uptake and accumulation in roots of two rice cultivars

566 under $400 \mu \mathrm{M} \mathrm{Al}$ toxicity.

\begin{tabular}{llllllll}
\hline \multirow{2}{*}{ Treatment } & $\mathbf{M g}$ & $\mathbf{A l}$ & $\mathbf{K}$ & $\mathbf{C a}$ & $\mathbf{M n}$ & $\mathbf{F e}$ & $\mathbf{Z n}$ \\
\cline { 2 - 8 } & $\mathbf{m g} / \mathbf{g}$ & $\mathbf{m g} / \mathbf{g}$ & $\mathbf{m g} / \mathbf{l}$ & $\mathbf{m g} / \mathbf{l}$ & $\mathbf{m g} / \mathbf{l}$ & $\mathbf{m g} / \mathbf{l}$ & $\mathbf{m g} / \mathbf{l}$ \\
\hline $\mathrm{CY} 927-\mathrm{H}_{2} \mathrm{O}$ & $2.34 \mathrm{a} \pm 0.17$ & - & $19.69 \mathrm{a} \pm 1.42$ & $0.88 \mathrm{a} \pm 0.34$ & $0.08 \mathrm{a} \pm 0.01$ & $6.16 \mathrm{a} \pm 0.30$ & $0.08 \mathrm{~b} \pm 0.03$ \\
CY927-BRs & $1.52 \mathrm{c} \pm 0.53$ & - & $14.21 \mathrm{ab} \pm 2.73$ & $0.51 \mathrm{~b} \pm 0.33$ & $0.07 \mathrm{~b} \pm 0.02$ & $4.19 \mathrm{ab} \pm 1.06$ & $0.12 \mathrm{a} \pm 0.05$ \\
CY927-Al & $1.14 \mathrm{~d} \pm 0.49$ & $5.02 \mathrm{a} \pm 2.34$ & $9.81 \mathrm{~b} \pm 0.29$ & $0.21 \mathrm{bc} \pm 0.05$ & $0.03 \mathrm{~b} \pm 0.01$ & $0.52 \mathrm{~b} \pm 0.23$ & $0.14 \mathrm{a} \pm 0.05$ \\
CY927-BRs $+\mathrm{Al}$ & $1.19 \mathrm{~b} \pm 0.42$ & $3.92 \mathrm{~b} \pm 1.23$ & $12.60 \mathrm{ab} \pm 1.10$ & $0.11 \mathrm{c} \pm 0.04$ & $0.04 \mathrm{~b} \pm 0.02$ & $0.46 \mathrm{~b} \pm 0.17$ & $0.07 \mathrm{~b} \pm 0.01$
\end{tabular}




$\begin{array}{lccccccc}\text { YLY689- } \mathrm{H}_{2} \mathrm{O} & 1.77 \mathrm{~b} \pm 0.50 & - & 13.48 \mathrm{~b} \pm 1.29 & 1.31 \mathrm{~b} \pm 1.25 & 0.07 \mathrm{a} \pm 1.25 & 4.03 \mathrm{a} \pm 0.94 & 0.02 \mathrm{c} \pm 0.01 \\ \text { YLY689-BRs } & 2.13 \mathrm{a} \pm 0.43 & - & 17.46 \mathrm{a} \pm 2.10 & 0.76 \mathrm{~b} \pm 0.17 & 0.05 \mathrm{ab} \pm 0.17 & 3.63 \mathrm{a} \pm 1.95 & 0.03 \mathrm{c} \pm 0.00 \\ & 1.28 \mathrm{~cd} \pm 0.34 & 8.78 \mathrm{a} \pm 0.25 & 13.47 \mathrm{~b} \pm 2.94 & 0.30 \mathrm{~b} \pm 0.17 & 0.04 \mathrm{ab} \pm 0.17 & 1.53 \mathrm{~b} \pm 0.17 & 0.04 \mathrm{~b} \pm 0.00 \\ \text { YLY689-Al } & 1.32 \mathrm{c} \pm 0.76 & 7.50 \mathrm{ab} \pm 2.45 & 11.02 \mathrm{bc} \pm 1.74 & 1.50 \mathrm{a} \pm 0.43 & 0.03 \mathrm{ab} \pm 0.43 & 0.71 \mathrm{~b} \pm 0.24 & 0.05 \mathrm{a} \pm 0.01 \\ \text { YLY689-BRs+Al } & & & & & & & \end{array}$

567 Each value is demonstrating the mean of three repeats of every treatment. Same letters are representing no

568 significant differentiation at $95 \%$ probability level $(\mathrm{p}<0.05)$

\section{$569 \quad$ Figure legends}

570 Fig. 1. Physiological effect of Al toxicity on rice cultivar CY-927 and mitigation effect by $0.01 \mu \mathrm{M}$ BRs under

$571400 \mu \mathrm{M}$ Al stress

572 Fig. 2. Physiological effect of Al toxicity on rice cultivar YLY-689 and mitigation effect by $0.01 \mu \mathrm{M}$ BRs under

$573400 \mu \mathrm{M}$ Al stress

574 Fig.3. Seed priming effect with $0.01 \mu \mathrm{M}$ BRs on (A) Chlorophyll a, (B) Chlorophyll b (C) Chlorophyll a+b in

575 leaves of two different cultivars of Oryza sativa under $400 \mu \mathrm{M}$ Al concentration

576 Fig. 4. Seed priming effect with $0.01 \mu \mathrm{M}$ BRs on MDA contents and $\mathrm{H}_{2} \mathrm{O}_{2}$ production in shoots and roots of

577 two rice cultivars under $400 \mu \mathrm{M}$ Al toxicity.

578 Fig. 5. Seed priming effect with $0.01 \mu \mathrm{M}$ BRs on SOD, CAT, APX and POD contents in both shoots and 579 roots of two rice cultivars under $400 \mu \mathrm{M}$ Al toxicity.

580 Fig. 6a. Effect of seed priming $0.01 \mu \mathrm{M}$ BRs on gene expression of (A) APX02, (B) APX08 in shoots and roots

581 of both cultivars of rice under toxicity of $400 \mu \mathrm{M} \mathrm{Al}$.

582 Fig. 6b. Effect of seed priming $0.01 \mu \mathrm{M}$ BRs on gene expression of (C) CATa, (D) CATb in shoots and roots 583 of both cultivars of rice under toxicity of $400 \mu \mathrm{M} \mathrm{Al}$. 
584 Fig. 6c. Effect of seed priming $0.01 \mu \mathrm{M}$ BRs on gene expression of (E) $S O D C u-Z n$, (F) $S O D-F e_{2}$ in shoots 585 and roots of both cultivars of rice under toxicity of $400 \mu \mathrm{M} \mathrm{Al}$.

586 Fig.7. Bioplot of principle component of 1 and 2 of the PCA extracted from results obtained from

587 physiological data of two different rice cultivars (CY927, YLY689) under various treatments such as control

588 primed with water (CY927- $\mathrm{H}_{2} \mathrm{O}$, YLY689- $\left.\mathrm{H}_{2} \mathrm{O}\right)$, control primed with BRs (CY927-BRs, YLY689-BRs), seed

589 primed with BRs, and treatment under $\mathrm{Al}$ stress (CY927-BRs+Al, YLY689-BRs $+\mathrm{Al}$ ), seed primed with $\mathrm{H}_{2} \mathrm{O}$

590 under $\mathrm{Al}$ stress $\left(\mathrm{CY} 92-\mathrm{Al}+\mathrm{H}_{2} \mathrm{O}\right.$, YLY689- $\left.\mathrm{Al}+\mathrm{H}_{2} \mathrm{O}\right)$. Sharp angle represented positive, obtuse angle showed

591 a negative correlation, as well as a right angle, demonstrated a correlation between parameters. (A)

592 Physiological parameters of rice variety CY927 illustration through Pearson's correlation coefficients under

593 different treatments. (I) contains POD, CAT, APX, and SOD, (II) Showed G.I, F/W, D/W, G.E, G.P, V.I, and

594 S.L, (III) Illustrated MDA, MGT, and H2O2; while (IV) represented R.L. (B) Physiological parameters of rice

595 variety YLY689 representation via Pearson's correlation coefficients under different treatments. Distance

596 between each circle represented the strength of correlation. . (I) contains POD, CAT, APX, and SOD, (II)

597 Showed G.I, F/W, D/W, G.E, G.P, and V.I, (III) Illustrated MDA, MGT, and H2O2; while (IV) represented

598 R.L and S.L (C) Dendrogram of two different rice cultivars under various treatments obtained through

599 Agglomerative hierarchical clustering using ward's method on basis of physiological traits. 


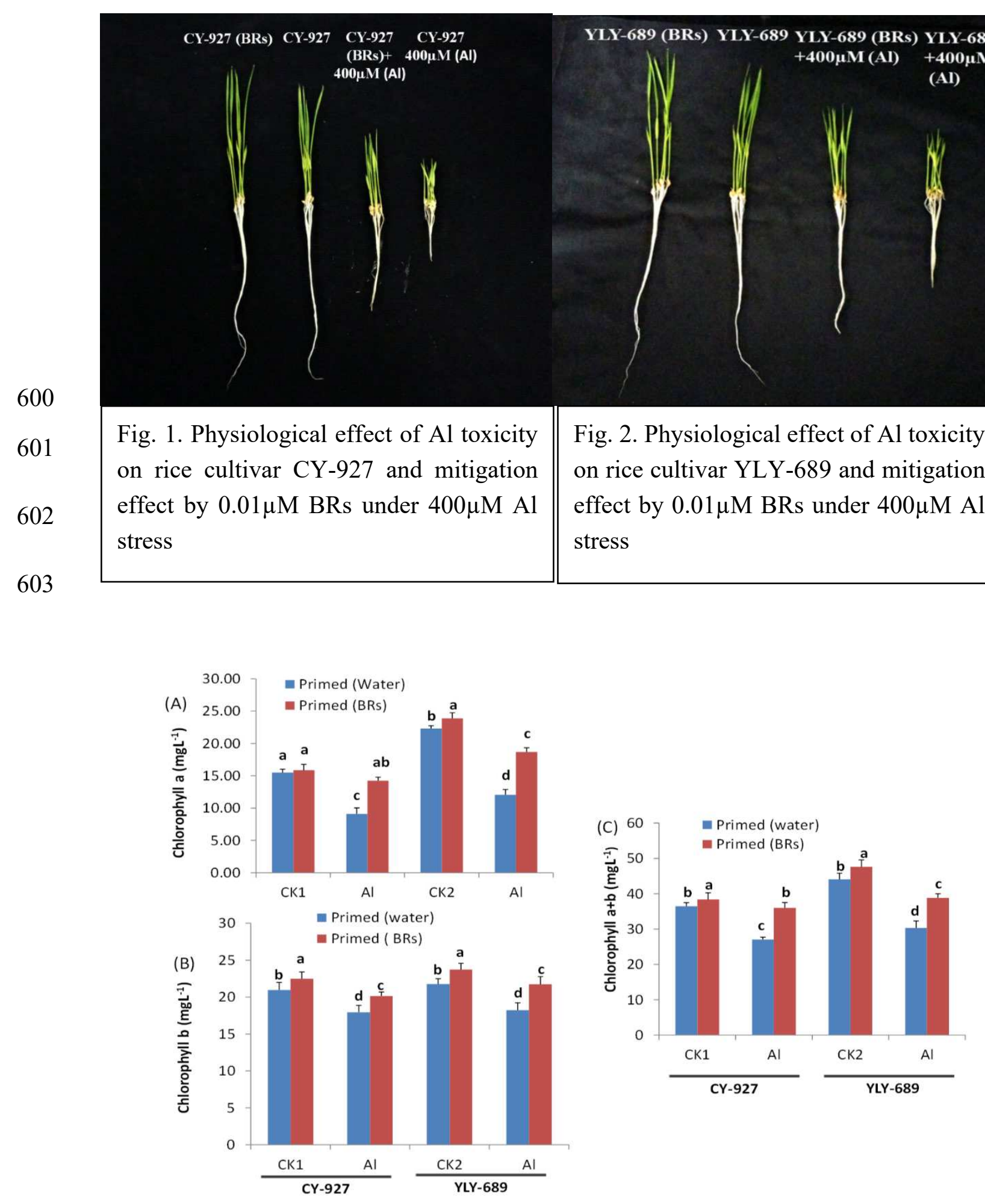

605 Fig.3. Seed priming effect with $0.01 \mu \mathrm{M}$ BRs on (A) Chlorophyll a, (B) Chlorophyll b (C) Chlorophyll a+b in 

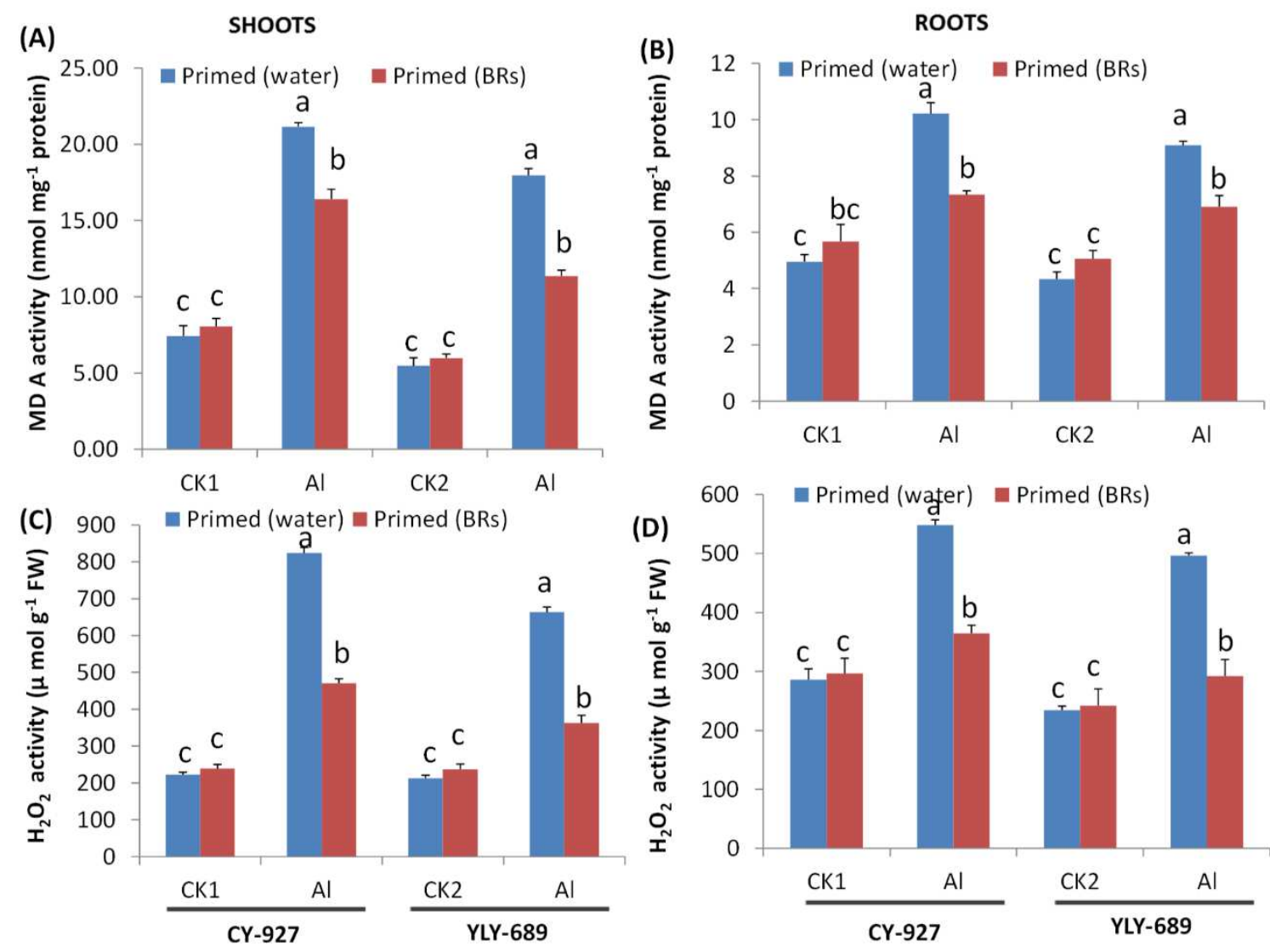

608 Fig. 4. Seed priming effect with $0.01 \mu \mathrm{M}$ BRs on MDA contents and $\mathrm{H}_{2} \mathrm{O}_{2}$ production in shoots and roots of 609 two rice cultivars under $400 \mu \mathrm{M}$ Al toxicity. 
(A)
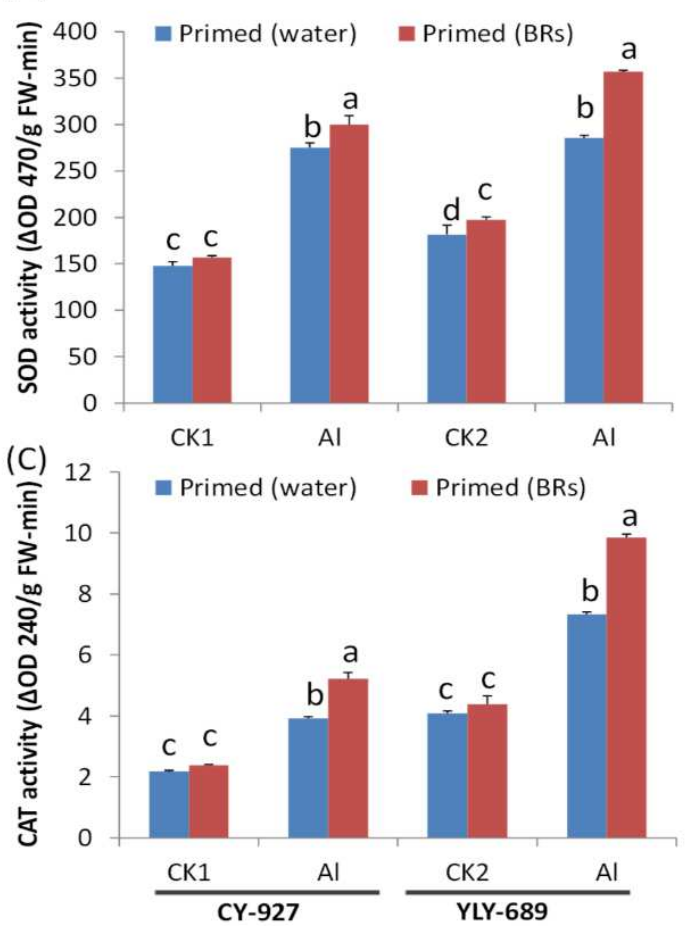

(E)

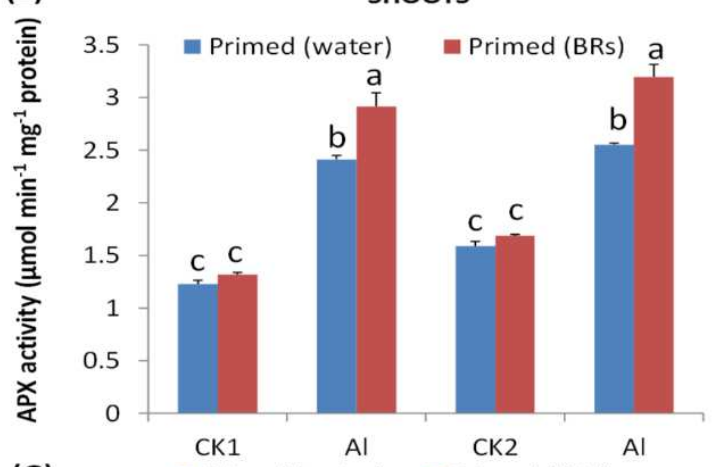

(G) 100 - Primed (water) = Primed (BRs)

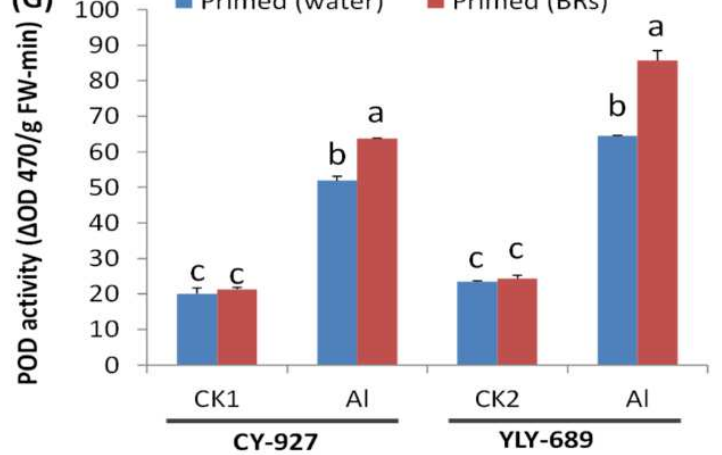

(B)

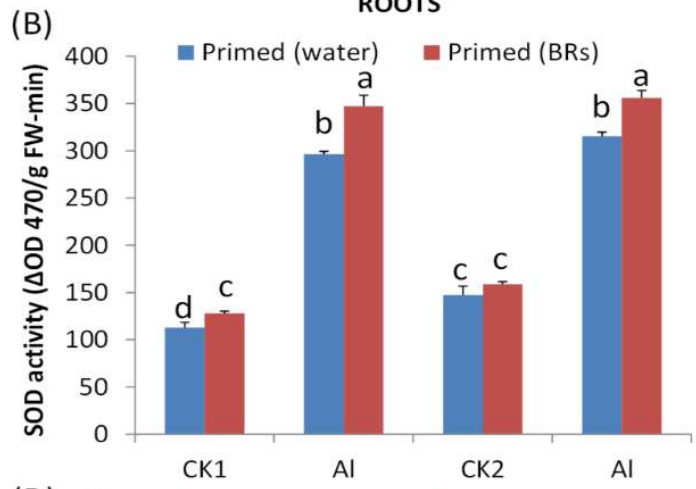

(D) 16$]$ Primed (water) $\quad$ Primed (BRs)

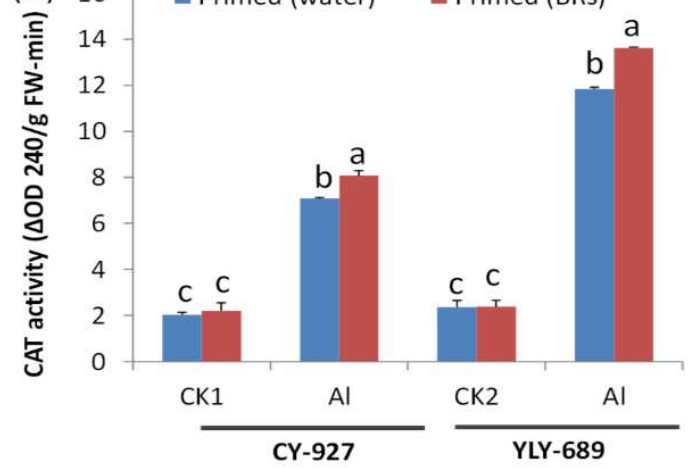

(F) ROOTS
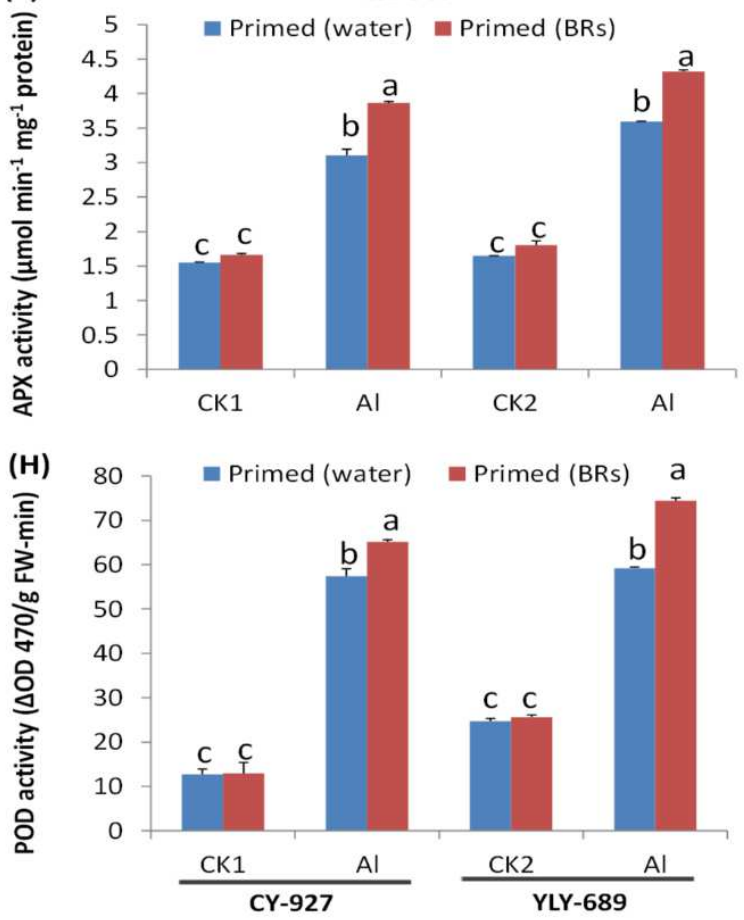

611 Fig. 5. Seed priming effect with $0.01 \mu \mathrm{M}$ BRs on SOD, CAT, APX and POD contents in both shoots and 612 roots of two rice cultivars under $400 \mu \mathrm{M} \mathrm{Al}$ toxicity. 

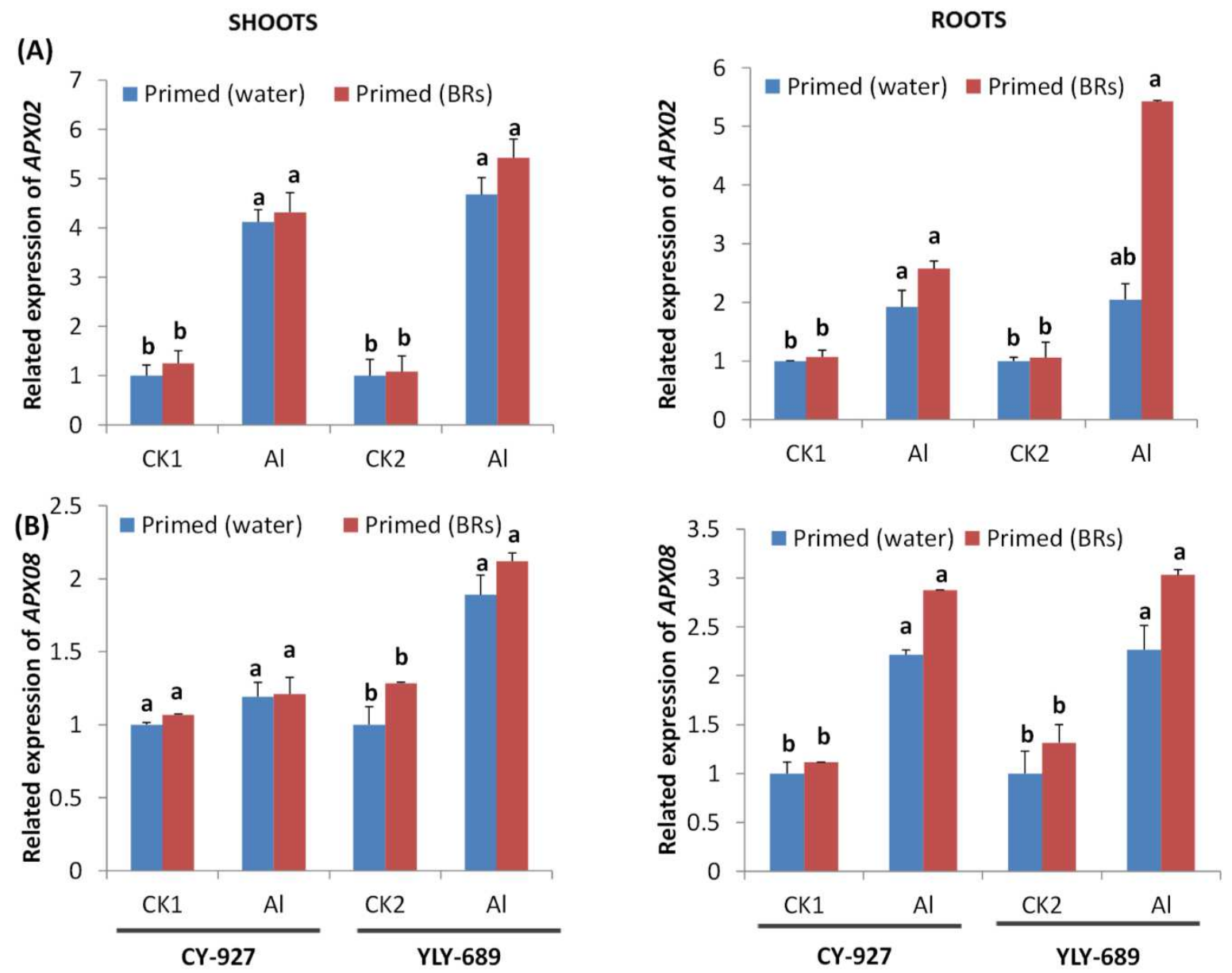

613

614 Fig. 6a. Effect of seed priming $0.01 \mu \mathrm{M}$ BRs on gene expression of (A) APX02, (B) APX08 in shoots and roots

615 of both cultivars of rice under toxicity of $400 \mu \mathrm{M} \mathrm{Al}$. 

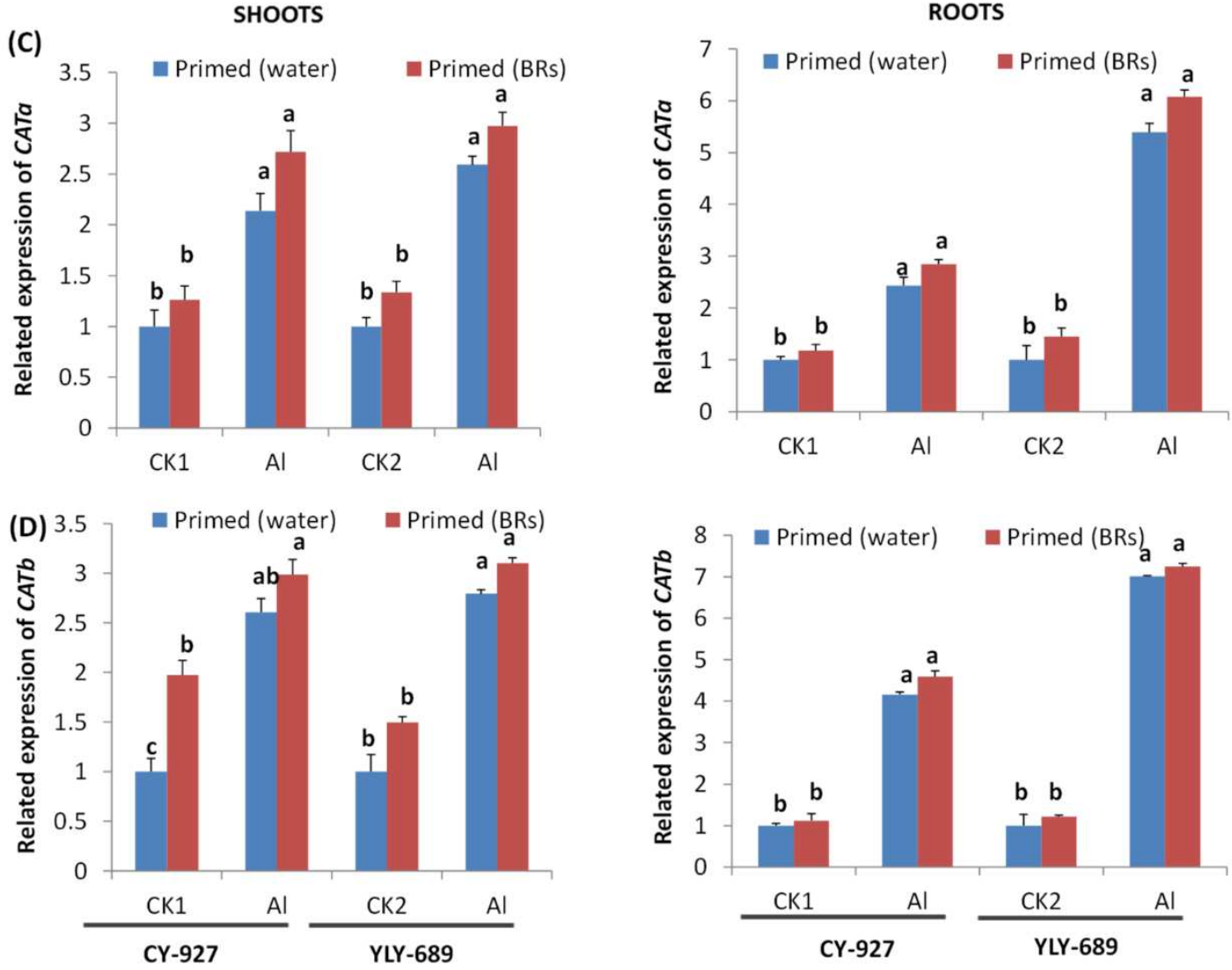

616

617 Fig. 6b. Effect of seed priming $0.01 \mu \mathrm{M}$ BRs on gene expression of (C) $C A T a$, (D) $C A T b$ in shoots and roots 618 of both cultivars of rice under toxicity of $400 \mu \mathrm{M} \mathrm{Al}$. 

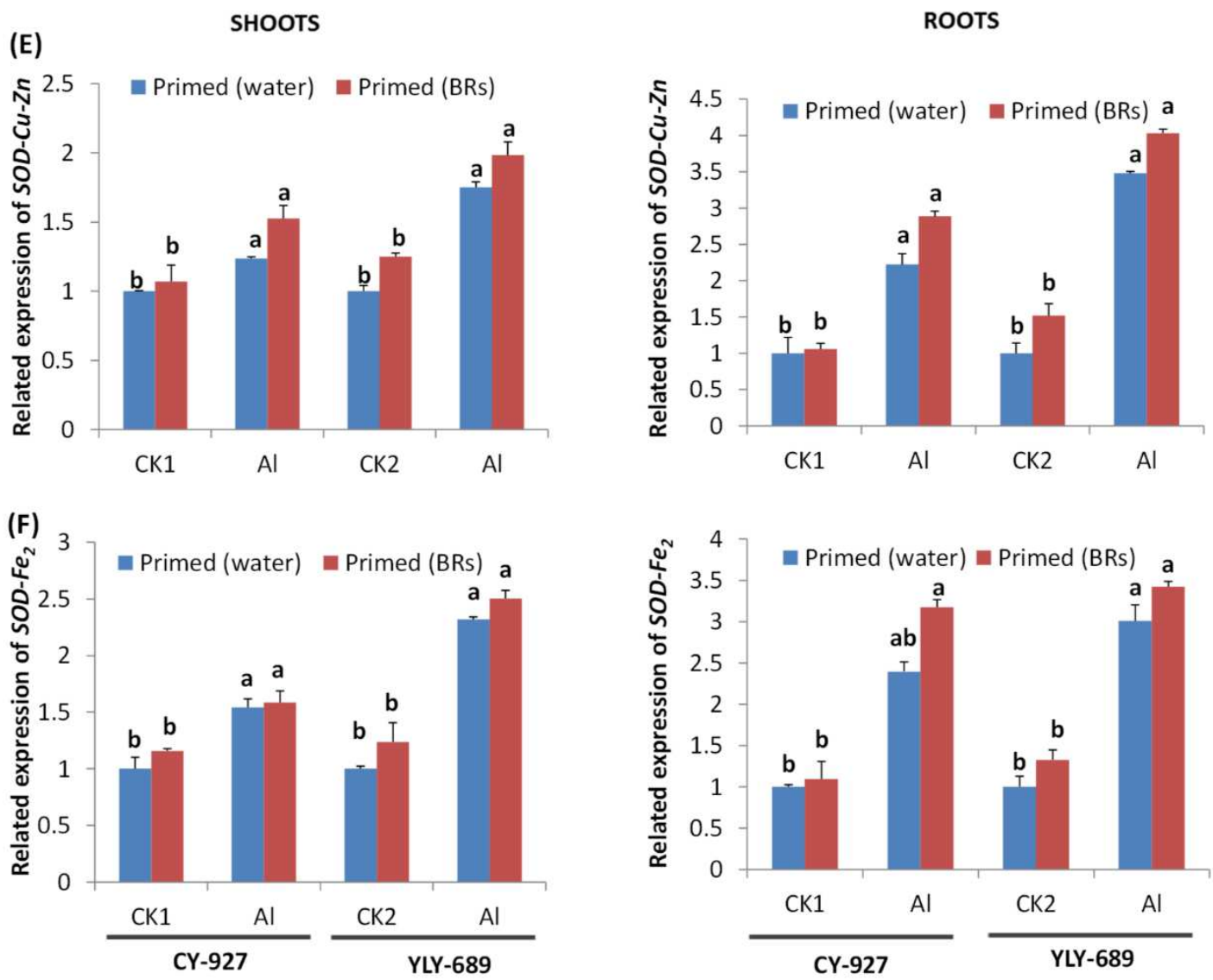

619

621 Fig. 6c. Effect of seed priming $0.01 \mu \mathrm{M}$ BRs on gene expression of (E) SOD Cu-Zn, (F) $S O D-F e_{2}$ in shoots and roots of both cultivars of rice under toxicity of $400 \mu \mathrm{M} \mathrm{Al}$. 

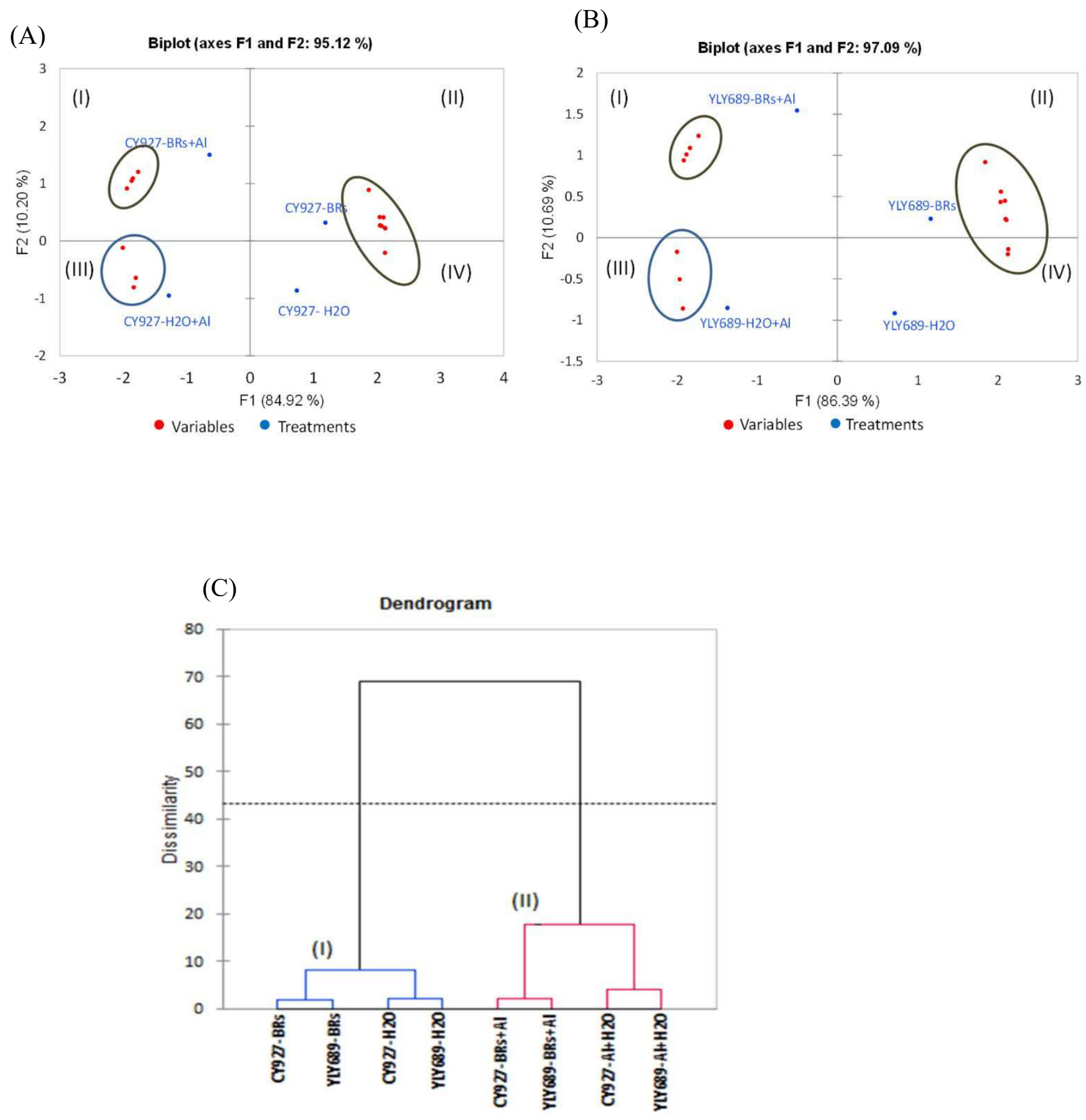

626 Fig.7. Bioplot of principle component of 1 and 2 of the PCA extracted from results obtained from

627 physiological data of two different rice cultivars (CY927, YLY689) under various treatments such as control

628 primed with water $\left(\mathrm{CY} 927-\mathrm{H}_{2} \mathrm{O}\right.$, YLY689- $\left.\mathrm{H}_{2} \mathrm{O}\right)$, control primed with BRs (CY927-BRs, YLY689-BRs), seed

629 primed with BRs, and treatment under $\mathrm{Al}$ stress (CY927-BRs+Al, YLY689-BRs $+\mathrm{Al}$ ), seed primed with $\mathrm{H}_{2} \mathrm{O}$ 
630 under $\mathrm{Al}$ stress $\left(\mathrm{CY} 92-\mathrm{Al}+\mathrm{H}_{2} \mathrm{O}\right.$, YLY689- $\left.\mathrm{Al}+\mathrm{H}_{2} \mathrm{O}\right)$. Sharp angle represented positive, obtuse angle showed

631 a negative correlation, as well as a right angle, demonstrated a correlation between parameters. (A)

632 Physiological parameters of rice variety CY927 illustration through Pearson's correlation coefficients under

633 different treatments. (I) contains POD, CAT, APX, and SOD, (II) Showed G.I, F/W, D/W, G.E, G.P, V.I, and

634 S.L, (III) Illustrated MDA, MGT, and $\mathrm{H}_{2} \mathrm{O}_{2}$; while (IV) represented R.L. (B) Physiological parameters of rice

635 variety YLY689 representation via Pearson's correlation coefficients under different treatments. Distance

636 between each circle represented the strength of correlation. . (I) contains POD, CAT, APX, and SOD, (II)

637 Showed G.I, F/W, D/W, G.E, G.P, and V.I, (III) Illustrated MDA, MGT, and $\mathrm{H}_{2} \mathrm{O}_{2}$; while (IV) represented

638 R.L and S.L (C) Dendrogram of two different rice cultivars under various treatments obtained through

639 Agglomerative hierarchical clustering using ward's method on basis of physiological traits. 


\section{Figures}

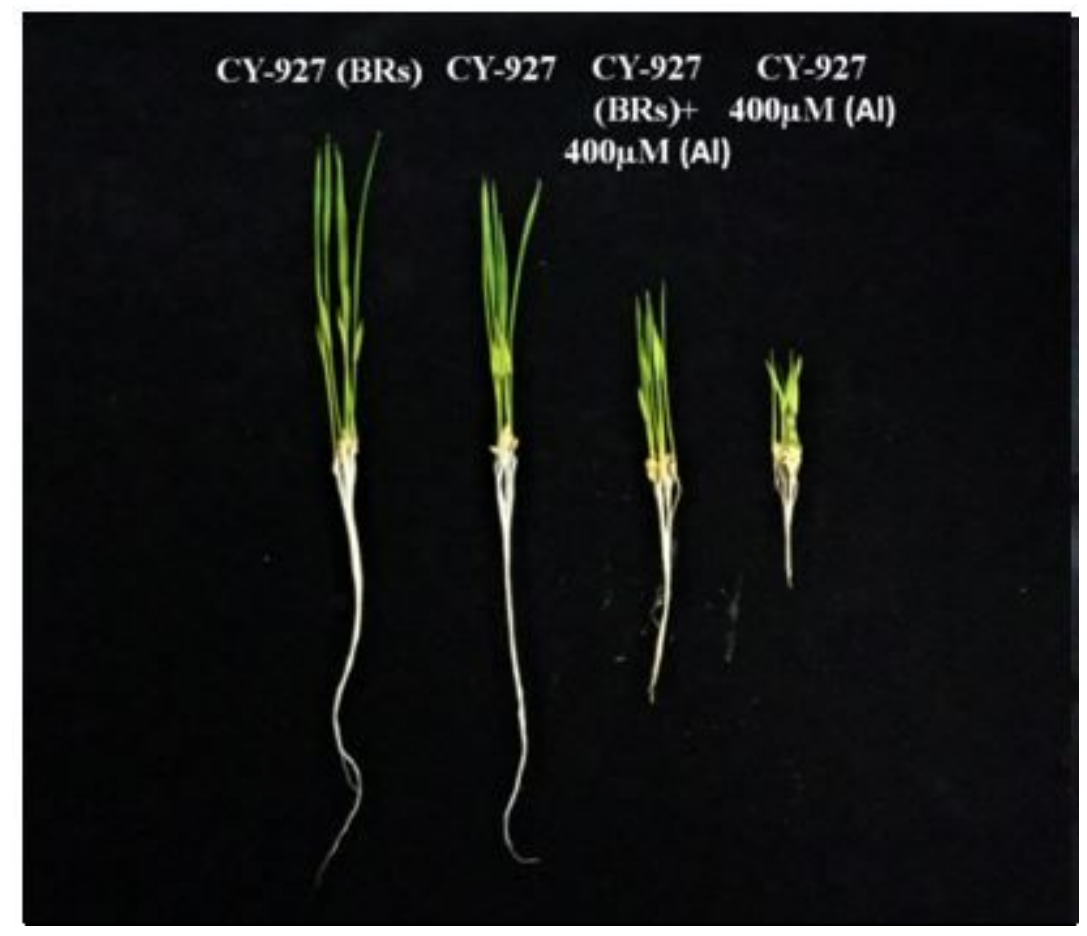

Figure 1

Physiological effect of Al toxicity on rice cultivar $\mathrm{CY}-927$ and mitigation effect by $0.01 \mu \mathrm{M}$ BRs under $400 \mu \mathrm{M}$ Al stress

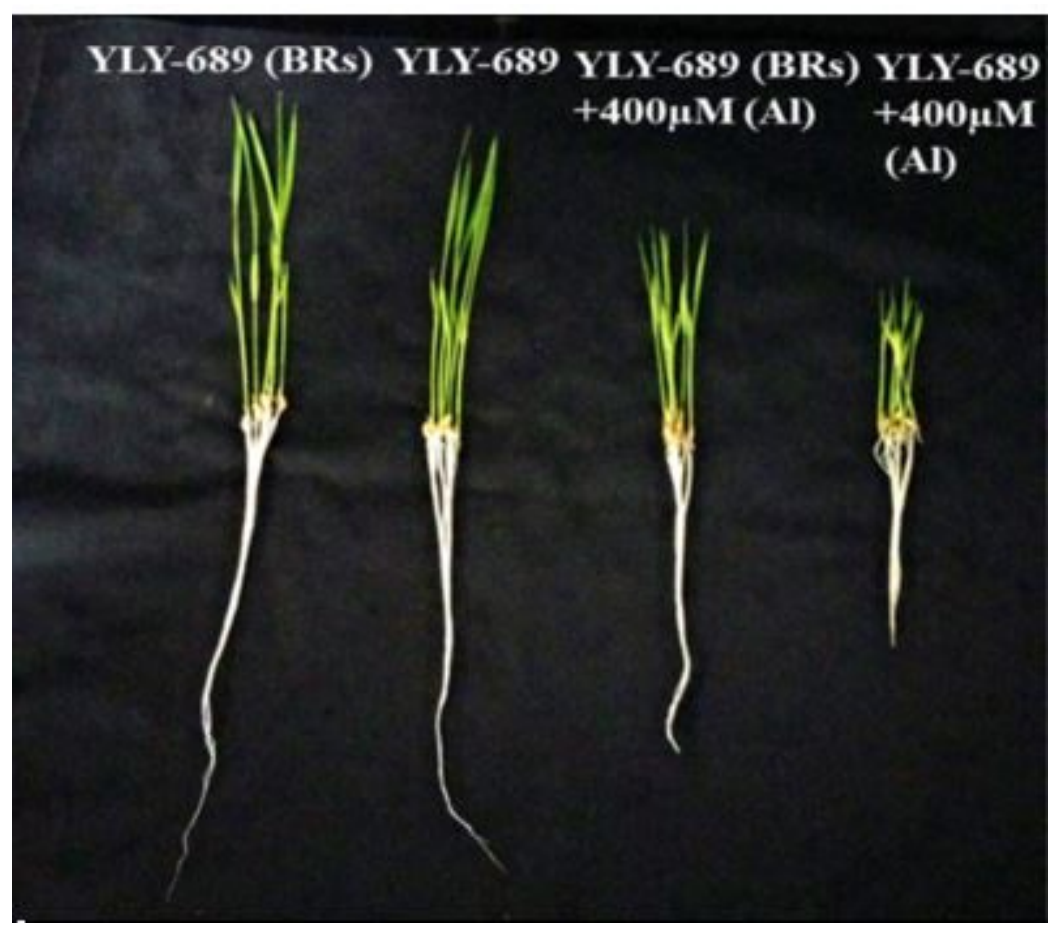

Figure 2 
Physiological effect of Al toxicity on rice cultivar YLY-689 and mitigation effect by $0.01 \mu \mathrm{M}$ BRs under $400 \mu \mathrm{M}$ Al stress

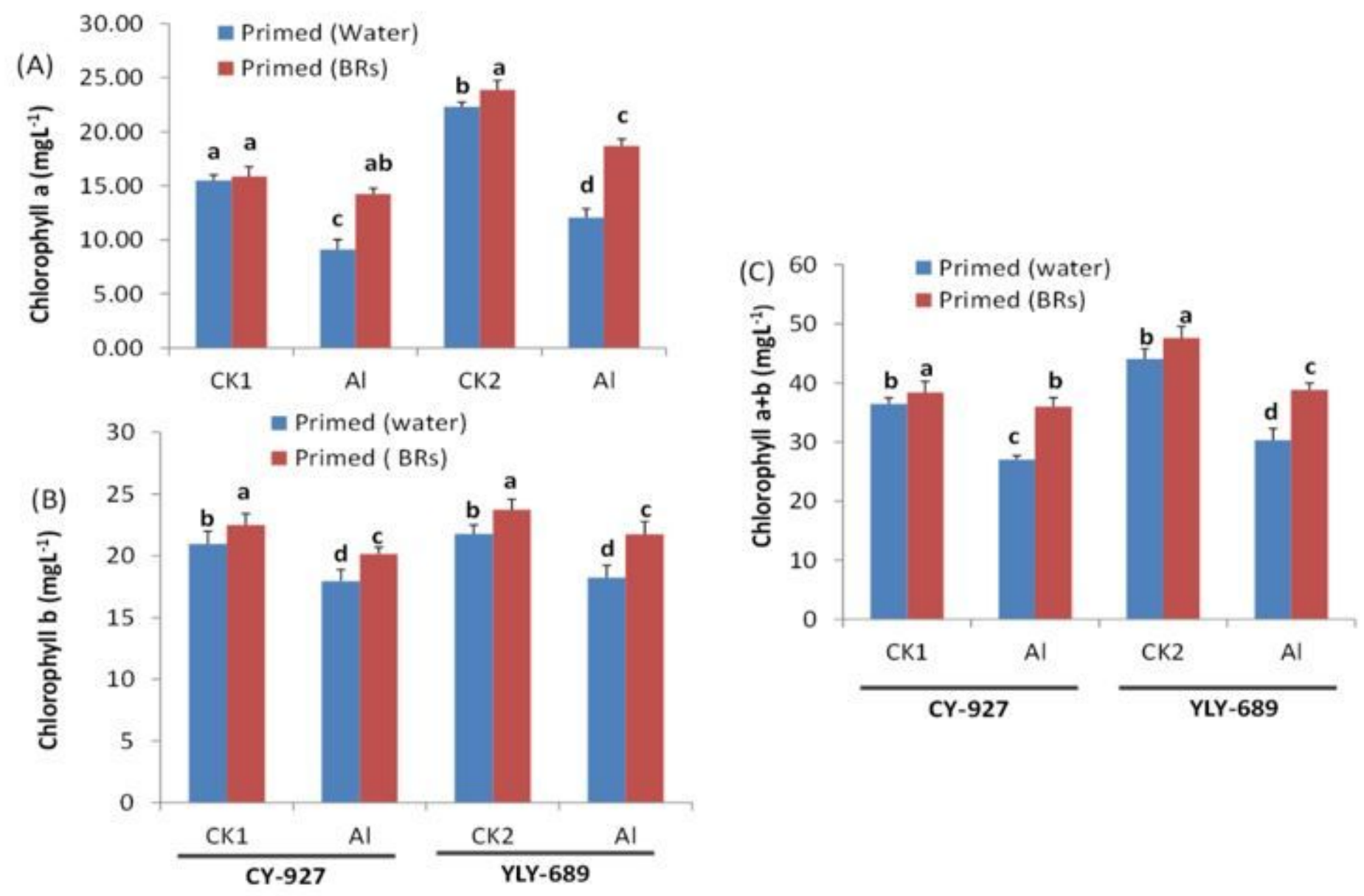

Figure 3

Seed priming effect with $0.01 \mu \mathrm{M}$ BRs on (A) Chlorophyll a, (B) Chlorophyll b (C) Chlorophyll $a+b$ in leaves of two different cultivars of Oryza sativa under $400 \mu \mathrm{M}$ Al concentration 

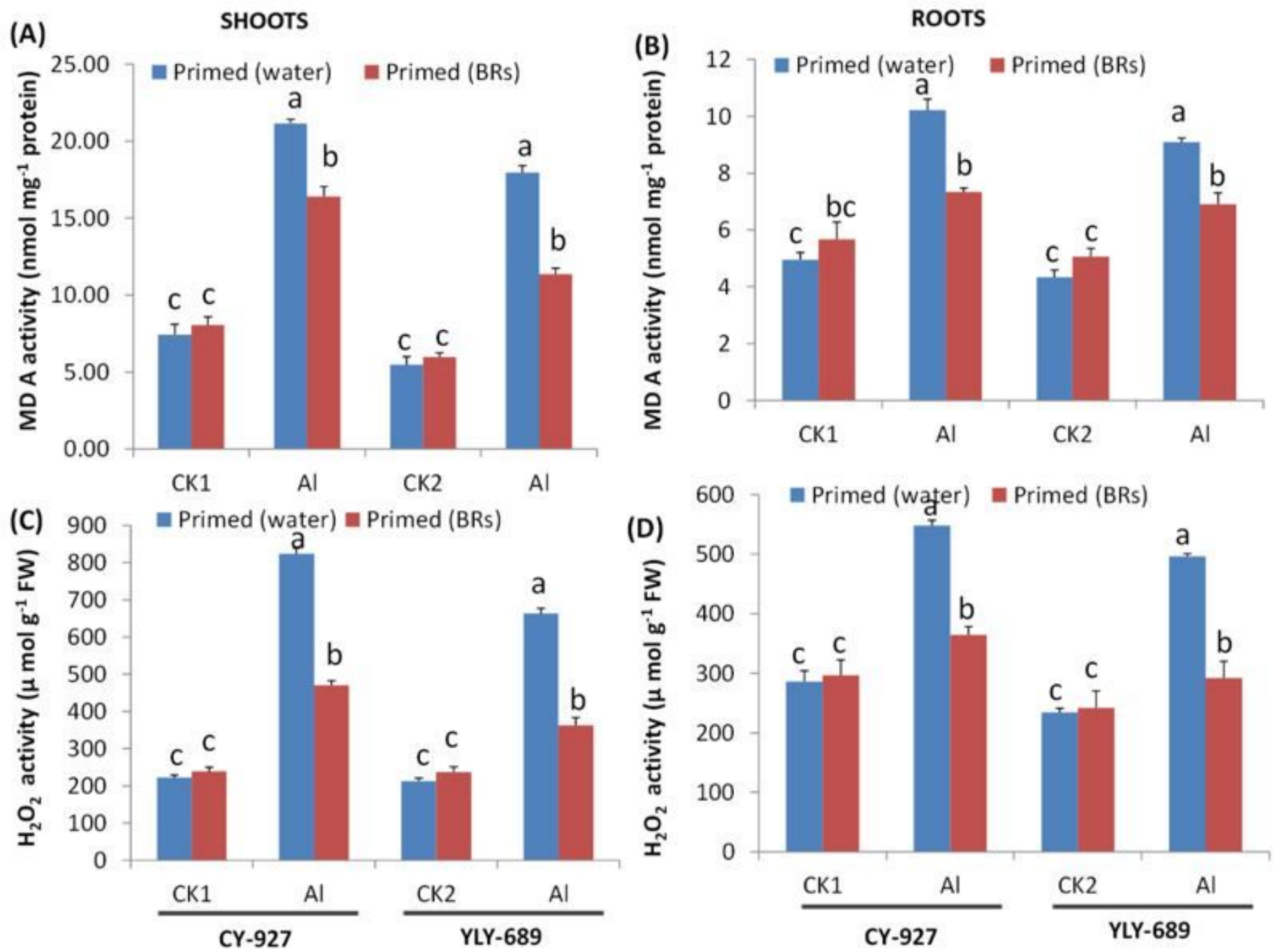

Figure 4

Seed priming effect with $0.01 \mu \mathrm{M}$ BRs on MDA contents and $\mathrm{H} 2 \mathrm{O} 2$ production in shoots and roots of two rice cultivars under $400 \mu \mathrm{M}$ Al toxicity. 
(A)
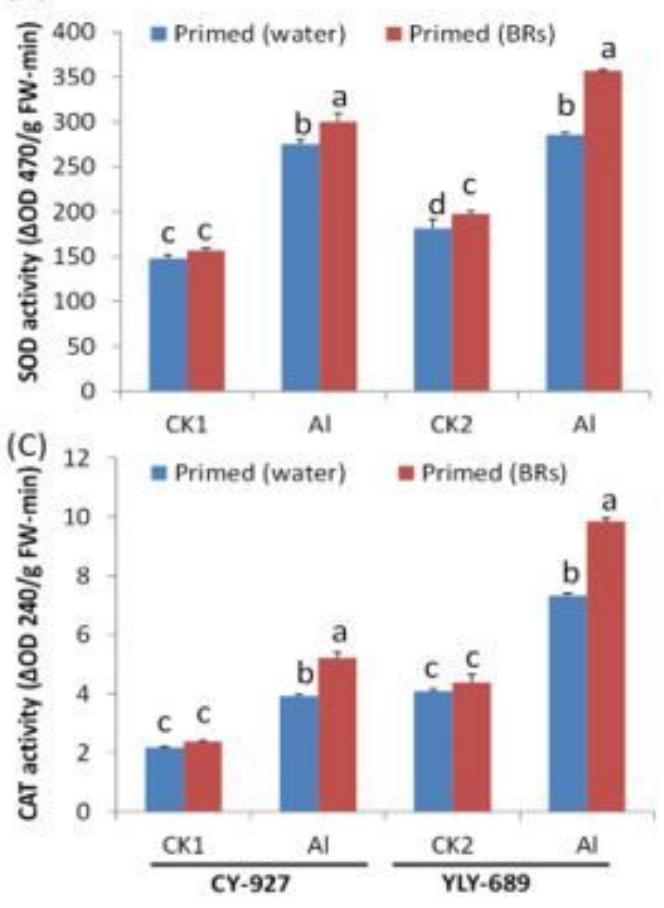

(E)
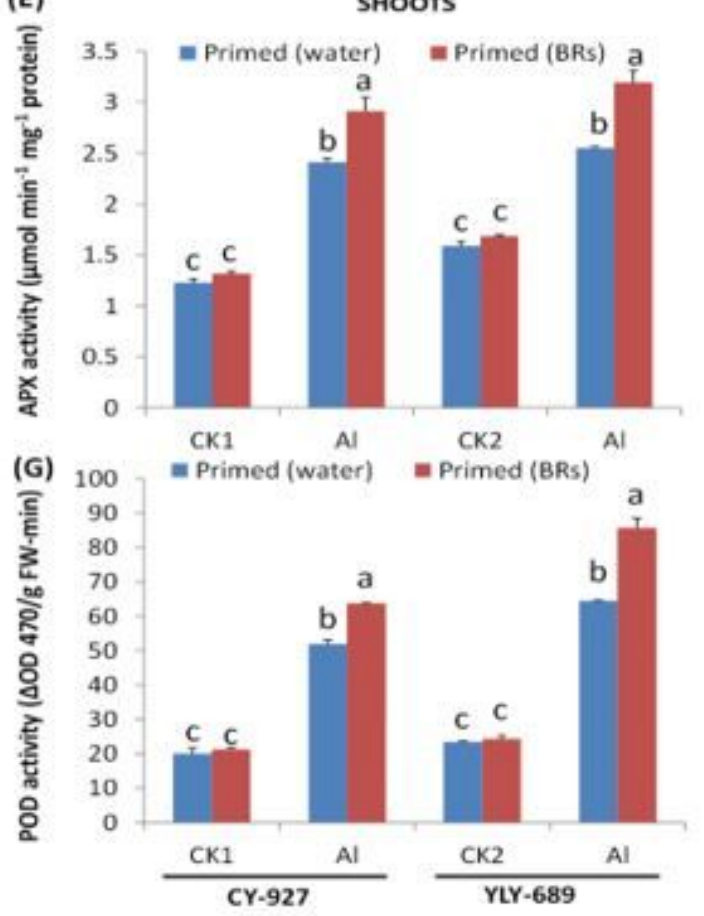

(B) ROOTS

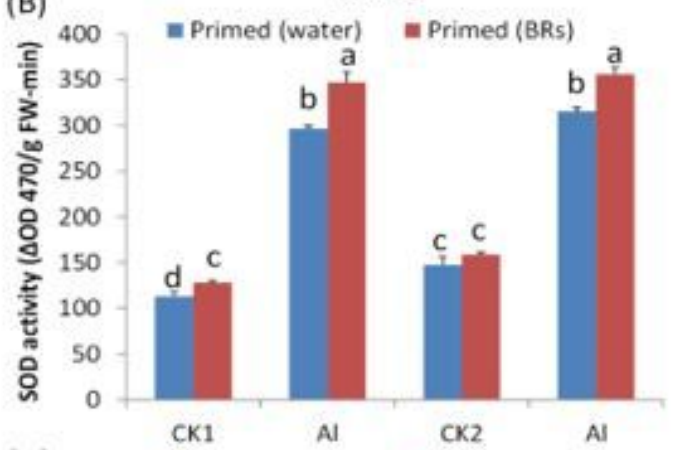

(D) $167=$ Primed (water) = Primed (BRs)

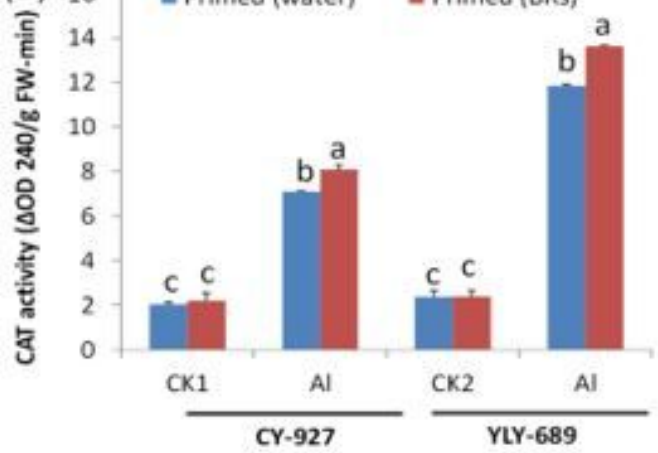

(F) ROOTS
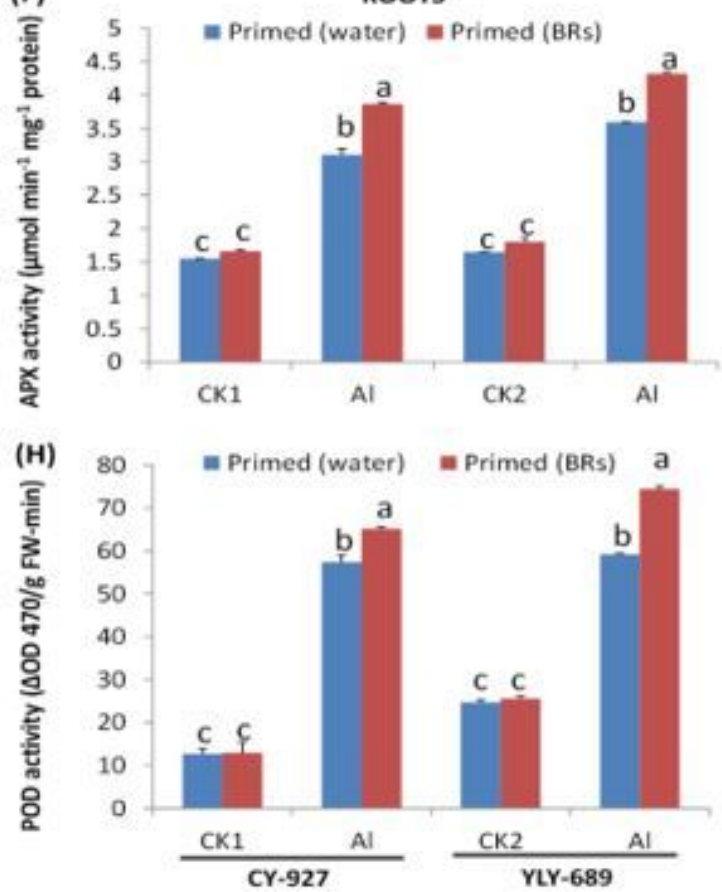

\section{Figure 5}

Seed priming effect with $0.01 \mu \mathrm{M}$ BRs on SOD, CAT, APX and POD contents in both shoots and roots of two rice cultivars under $400 \mu \mathrm{M}$ Al toxicity. 

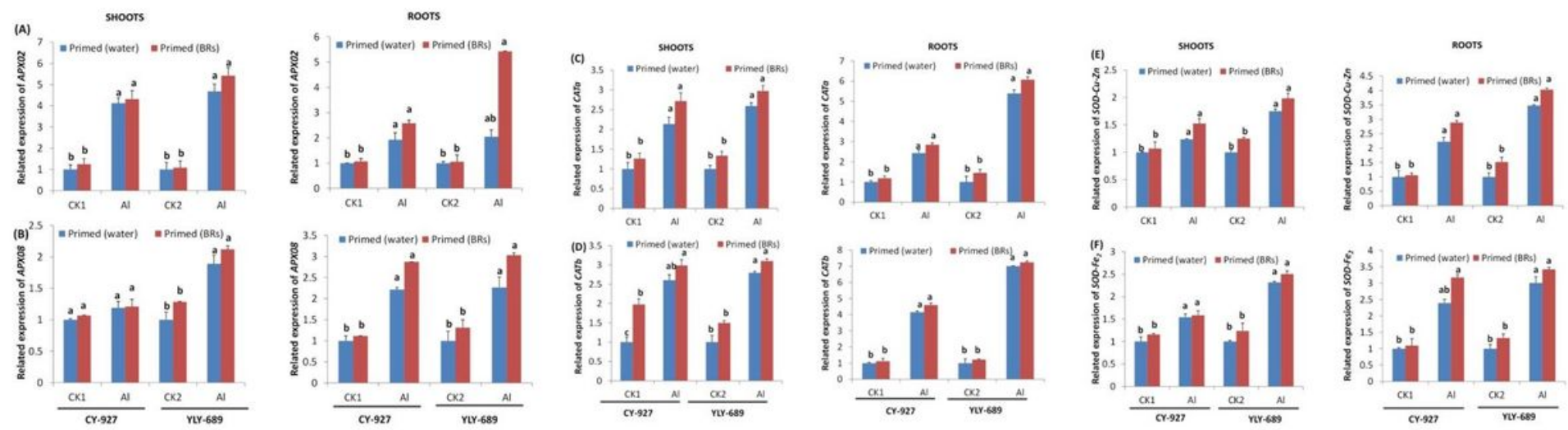

Figure 6

Fig. 6a. Effect of seed priming $0.01 \mu \mathrm{M}$ BRs on gene expression of (A) APX02, (B) APX08 in shoots and roots of both cultivars of rice under toxicity of $400 \mu \mathrm{M}$ Al. Fig. $6 \mathrm{~b}$. Effect of seed priming $0.01 \mu \mathrm{M}$ BRs on gene expression of (C) CATa, (D) CATb in shoots and roots of both cultivars of rice under toxicity of $400 \mu \mathrm{M}$ Al. Fig. 6c. Effect of seed priming $0.01 \mu \mathrm{M}$ BRs on gene expression of (E) SOD Cu-Zn, (F) SOD-Fe2 in shoots and roots of both cultivars of rice under toxicity of $400 \mu \mathrm{M} \mathrm{Al}$. 
(A)

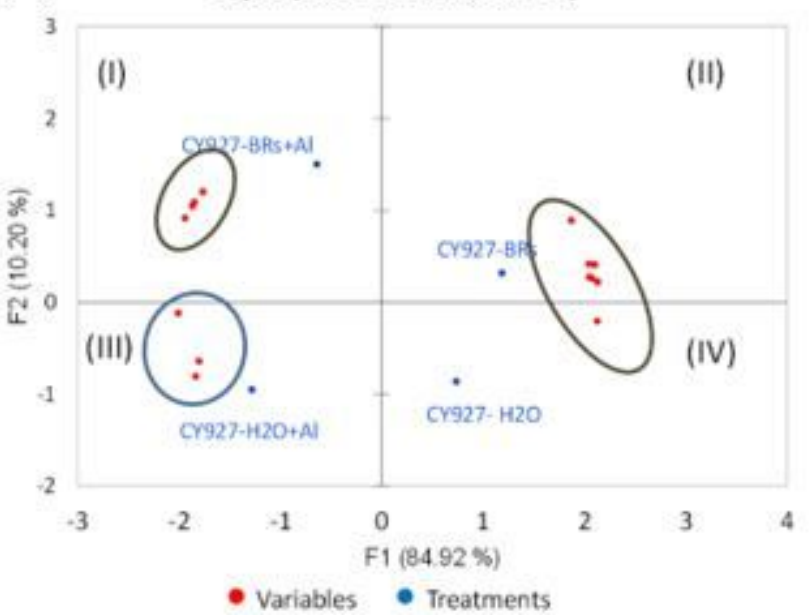

(B)

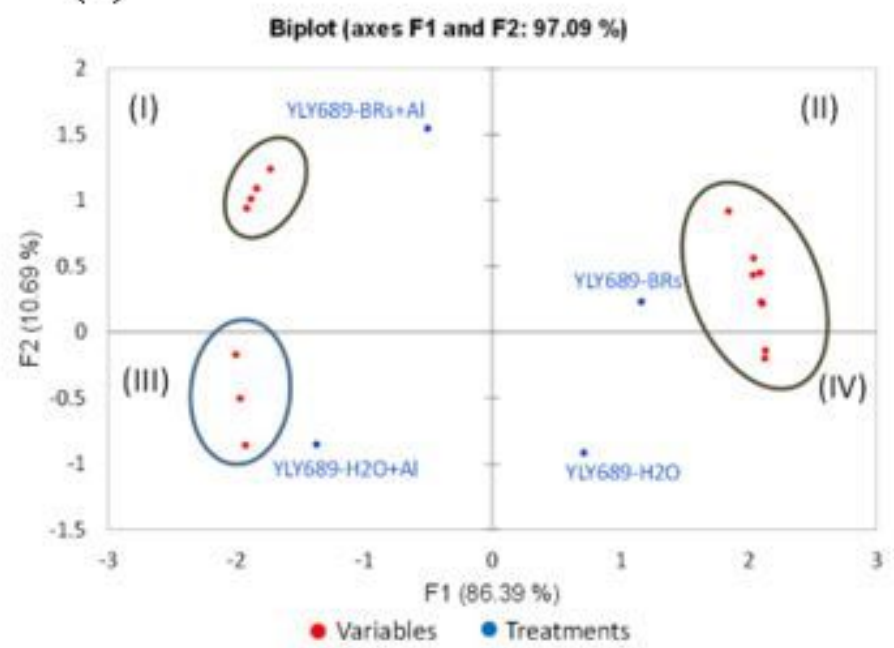

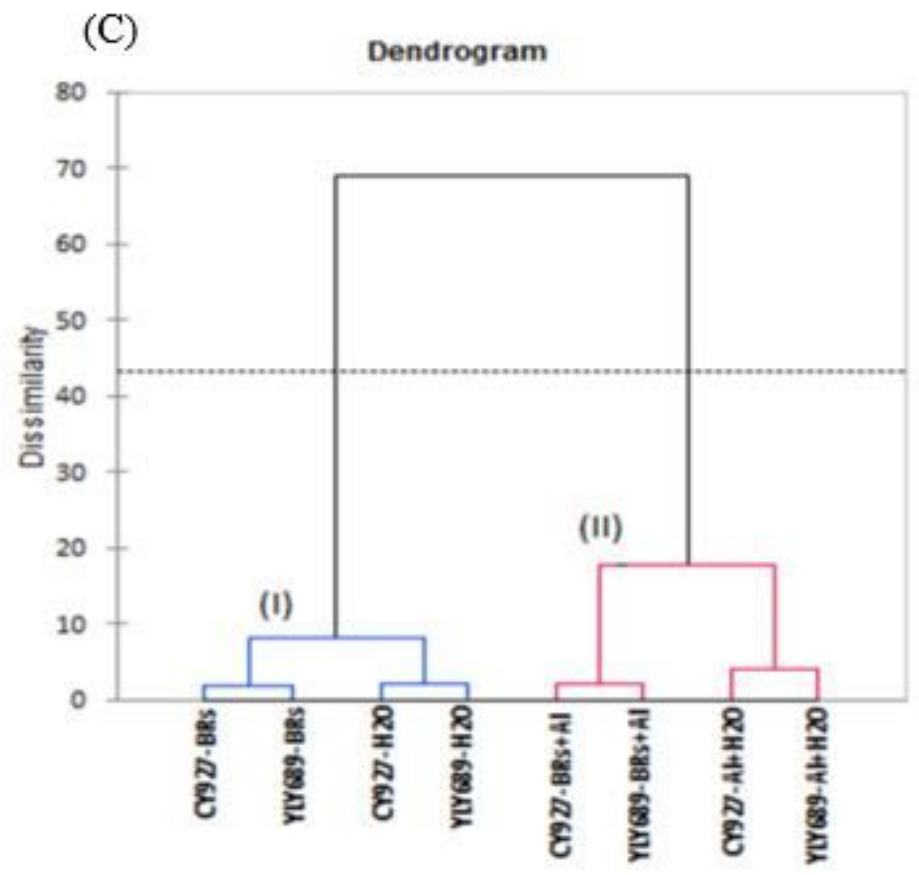

Figure 7

Bioplot of principle component of 1 and 2 of the PCA extracted from results obtained from physiological data of two different rice cultivars (CY927, YLY689) under various treatments such as control primed with water (CY927-H2O, YLY689-H2O), control primed with BRs (CY927-BRs, YLY689-BRs), seed primed with $\mathrm{BRs}$, and treatment under Al stress (CY927-BRs+Al, YLY689-BRs+Al), seed primed with $\mathrm{H} 2 \mathrm{O}$ under $\mathrm{Al}$ stress(CY92-Al+ H2O, YLY689- Al+ H2O). Sharp angle represented positive, obtuse angle showed a negative correlation, as well as a right angle, demonstrated a correlation between parameters. (A) Physiological parameters of rice variety CY927 illustration through Pearson's correlation coefficients 
under different treatments. (I) contains POD, CAT, APX, and SOD, (II) Showed G.I, F/W, D/W, G.E, G.P, V.I, and S.L, (III) Illustrated MDA, MGT, and H2O2; while (IV) represented R.L. (B) Physiological parameters of rice variety YLY689 representation via Pearson's correlation coefficients under different treatments.

Distance between each circle represented the strength of correlation. . (I) contains POD, CAT, APX, and SOD, (II) Showed G.I, F/W, D/W, G.E, G.P, and V.I, (III) Illustrated MDA, MGT, and H2O2; while (IV) represented R.L and S.L (C) Dendrogram of two different rice cultivars under various treatments obtained through Agglomerative hierarchical clustering using ward's method on basis of physiological traits.

\section{Supplementary Files}

This is a list of supplementary files associated with this preprint. Click to download.

- supplementaryFile.docx 